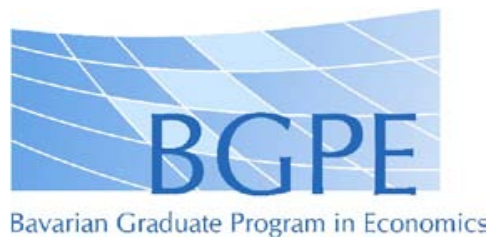

BGPE Discussion Paper

No. 131

\title{
Intermediated vs. Direct Sales and a No-Discrimination Rule
}

\section{Sebastian Wismer}

January 2013

ISSN 1863-5733

Editor: Prof. Regina T. Riphahn, Ph.D.

Friedrich-Alexander-University Erlangen-Nuremberg

(c) Sebastian Wismer 


\title{
Intermediated vs. Direct Sales and a No-Discrimination Rule*
}

\author{
Sebastian Wismer ${ }^{\dagger}$
}

This version: January 2013

First version: February 2012

\begin{abstract}
When sellers join a platform to sell their products, the platform operator may restrict their strategic decisions. In fact, several platform operators impose most-favored treatment or no-discrimination rules (NDRs), asking sellers not to offer better sales conditions elsewhere.

In this paper, I analyze a model that allows for an endogenous split-up of consumers between sales channels. Competing sellers might set different prices across channels, depending on the platform tariff and presence of a NDR. I find that the platform operator imposes a NDR if he faces high transaction costs, if seller competition is weak, and if the initial distribution of consumers on channels is strongly skewed. Prohibiting NDRs can have both positive and negative effects on welfare.
\end{abstract}

Keywords: Intermediation, Platform pricing, No-discrimination rule JEL classification numbers: D40, L42, L81

\footnotetext{
*I am grateful to Norbert Schulz and Peter Welzel for insightful guidance and continuous encouragement. I also thank Florian Englmaier, Johannes Muthers, and participants of the 39th Annual Conference of the EARIE (Rome, 2012) and the 13th BGPE research workshop for helpful comments.

${ }^{\dagger}$ Bavarian Graduate Program in Economics, University of Wuerzburg, Industrial Economics, Sanderring 2, 97070 Wuerzburg, Germany, sebastian.wismer@uni-wuerzburg.de
} 


\section{Introduction}

Sellers often simultaneously use several ways of distribution or sales channels to reach consumers. Different channels are likely to differ in transaction costs. Furthermore, each consumer's willingness to pay for a specific product may depend on the channel used for purchase. Consequently, sellers usually face incentives to set different prices across channels 1 However, if a seller joins a marketplace offered by an intermediary, the intermediary may restrict the seller's pricing decisions. More specifically, an intermediary who has (some) market power may prohibit sellers offering customers better sales conditions elsewhere, in particular selling the same product at a lower price in other sales channels, by imposing a most-favored treatment or no-discrimination clause.

For example, HRS, the leading German online hotel reservation platform, only lists hotels which agree to offer the best room rates and most favorable booking conditions on the HRS platform. Several other online travel agents (e.g. Booking.com and Expedia) limit hotels' decisions on room rates in a similar way. Furthermore, in May 2010, Amazon's European platforms introduced a price parity rule where they ask sellers who offer their products in Amazon's marketplaces not to set lower prices for these products elsewhere. A similar rule has applied to the US marketplace (Amazon.com) for several years. Both Amazon's price parity rule and the most-favored treatment clauses imposed by HRS and other platforms of online travel agents just recently became subjects of litigation 2

In all cases described above, many sellers (or hotels) 3 want to be listed on a platform, in particular to reach consumers who might not search for them outside the respective platform. At the same time, they also offer products outside the platform (using their own stores/websites or accepting direct requests from potential customers). The platform charges sellers considerable fees/commissions (primarily based on transaction volume), whereas direct sales typically generate different costs. Under a no-discrimination rule (NDR), sellers' prices usually cannot reflect all cost differences. Therefore, consumers who come to know that a seller uses several sales channels do not internalize differences in costs when choosing in which channel to buy as the (zero) price difference does not signal cost advantages. This problem can become even more severe if consumers are likely to search for offers in alternative channels of the same provider after they found a matching product in one channel: if sellers are free to set different prices across channels, they can steer consumers to the most profitable channel, in contrast to the situation under a no-discrimination rule. However, competing sellers may not perfectly internalize consumers' channel preferences and the intermediary's costs when setting their prices 4 Therefore, it is natural to ask about the con-

\footnotetext{
${ }^{1}$ Wolk and Ebling 2010 find that sellers indeed practice channel-based price differentiation.

${ }^{2}$ Cf. Office of Fair Trading (2012), Bundeskartellamt (2012), injunction against HRS's most-favored treatment clause (Higher Regional Court Duesseldorf, file no. 33 O 16/12), and appendix, p.26

${ }^{3}$ In the following, I use the terms "no-discrimination rule" (NDR) and "sellers" also as representatives for mostfavored treatment clauses and hotels, respectively.

${ }^{4}$ Furthermore, if the platform provides useful services (e.g. detailed product information, reviews, reduction of search costs) which require investments by the intermediary but also promote direct sales, this phenomenon
} 
sequences of no-discrimination rules on seller behavior, the split-up of consumers between channels, and the intermediary's decision on fees charged to sellers and buyers. However, to date, there is no study that explicitly addresses these consequences 5

In this paper, I analyze a framework of a dominant intermediary who offers sellers a platform to reach consumers. Sellers serve horizontally differentiated products and compete with each other. Each seller can offer her respective product both directly and in the marketplace operated by the intermediary. Consumers apply a sequential decision rule: they compare products based on prices in one of the two sales channels, choose their preferred product, and then decide in which channel to buy. In particular, this assumption introduces a certain spillover effect between channels: being active in one channel can lead to additional sales in the other channel 6 Taken together, I analyze a model that allows for an endogenous split-up of consumers between channels with competing sellers who might set different prices across channels. In this model, both consumers' and sellers' decisions are affected by the tariff chosen by the intermediary and his decision on imposing a no-discrimination rule.

Firstly, I find that without a no-discrimination rule the division of the intermediary's fee between sellers and buyers does not affect the split-up of consumers between channels: sellers fully internalize (transaction-based) fees charged to consumers when setting their prices 7 Without a no-discrimination rule, each seller's channel-dependent prices generally differ from each other. The price difference reflects cost differences, relative importance of each channel for product choice, and differences in consumers' channel valuations, resulting in a redistribution of consumers between channels.

Secondly, if the intermediary imposes a no-discrimination rule, his tariff system is no longer neutral. Furthermore, when deciding whether to join the platform, sellers trade-off the costs of providing a certain amount of their product over the platform with the benefits of reaching additional consumers on the platform. The intermediary imposes a nodiscrimination rule if his costs for processing a transaction are relatively high, if seller competition is weak, and if the initial distribution of consumers on channels is strongly skewed (in particular, if most consumers' product choice is based on prices on the platform). If these criteria are met, each seller's incentives to specialize on direct sales under a no-discrimination rule are relatively weak. Hence, the intermediary prefers imposing a no-discrimination rule, charging fees that are compatible with all sellers being active on his platform, to not imposing a no-discrimination rule. Each seller's outside option, specializing in direct sales and refusing to join the platform, implies less consumers being aware of her respective offer. However,

(which basically causes a free-riding effect) can lead to an inefficiently low level of such investments.

5 Aguzzoni et al. 2012) offer an up-to-date review of the literature on price relationship agreements and their potential effects, indicating that there is no study that examines such agreements in intermediated markets. For more details, cf. the literature section below.

${ }^{6}$ This effect (sometimes called "billboard effect") seems natural and is well-known at least in the hotel industry, cf. e.g. Anderson (2011). Furthermore, the assumption on sequential consumer decisions seems plausible as consumers rarely compare all prices of several products across channels. For a related empirical analysis of consumer search behavior across online book stores, cf. e.g. De Los Santos, Hortaçsu and Wildenbeest (2012).

${ }^{7}$ Note that this neutrality property does not necessarily hold for membership fees which consumers might pay up front as these can lead to an unravelling problem, cf.Gans 2012) and my literature review. 
specialization would also have a positive effect on seller profits: besides saving relatively high platform fees, it may relax seller competition.

Welfare implications depend on the difference between the intermediary's pertransaction costs and the costs sellers incur when selling directly to buyers, the distribution of consumers' heterogeneous valuations across channels, and the size of the initial fraction of platform consumers. Without a no-discrimination rule, both an over- and an underuse of the platform channel can arise. Imposing a no-discrimination rule always results in an underuse of the intermediary's marketplace; this is due to the basic inefficiency caused by the intermediary having market power. Consequently, prohibiting no-discrimination rules can have both positive and negative effects on welfare, even in a framework that excludes both service arguments and foreclosure effects.

\section{Related literature}

Considering the terminology used both by competition authorities and in my introduction (terms like "no-discrimination rules" and "most-favored customer clauses"), at first view my work may be seen as closely related to the literature on certain price relationship agreements in which a seller guarantees customers not to offer better conditions to any other customer (across-customers agreements or most-favored customer clauses) or not to offer conditions worse than those offered by competitors (across-sellers agreements like low-price guarantees) 8 However, the present studies focus on sellers who directly grant their customers some guarantee, excluding any form of intermediation between those two groups, while I analyze a specific form of a most-favored treatment clause imposed by an intermediary who offers a marketplace but does not control prices of the traded goods. In particular, Aguzzoni et al. (2012), who summarize potential effects of price-relationship agreements (PRAs), point out that they "have not found any economic literature that specifically studies the possible competition effects of third-party PRAs" 9 Furthermore, they state that "to date th[e] literature [on two-sided markets] does not study the competitive effects of across-platforms parity agreements.' 10

In line with the first statement, I am not aware of any study that specifically analyzes an intermediary's decision on imposing a no-discrimination rule (or concluding an "acrossplatforms parity agreement") in a framework with (imperfectly) competing sellers who may set different prices across channels. However, across-platforms parity agreements exhibit at least some similarities with so-called "no-surcharge rules" which payment card networks (as a specific kind of platform operators) may impose. Before reviewing related work on card networks and no-surcharge/no-discrimination rules, I firstly address studies on two-sided

\footnotetext{
${ }^{8}$ In particular, both across-customer and across-seller agreements can facilitate collusion (cf. e.g. Cooper, 1986; Neilson \& Winter, 1993; Schnitzer, 1994; Hviid \& Shaffer, 2010). Furthermore, price-matching guarantees may be used to signal a low price level (e.g. Moorthy \& Winter, 2006) or to deter entry (e.g. Arbatskava, 2001).

"Aguzzoni et al. (2012, p.84). Third-party PRAs include "across-platform parity agreements" which are concluded between sellers and a platform operator and limit sellers' pricing decisions.

10 Aguzzoni et al. (2012, p.96).
} 
markets and platform pricing.

\section{Platform markets}

The classical literature on two-sided market 11 (e.g. Rochet \& Tirole, 2006; Armstrong, 2006) basically discusses a platform's pricing behavior in reduced-form models that capture network effects through the number of members on the other side of the platform. Accordingly, each player's utility depends on everyone's joining decision. However, in the canonical models, utility does not depend on other decision variables of any member of the two sides of the market, in particular not on seller pricing in case of a trade platform.

However, there are a few recent exceptions which discuss proportional fees and, therefore, endogenize seller pricing (Shv \& Wang, 2011; Miao, 2011; Wang \& Wright, 2012; Muthers \& Wismer, 2013). Nevertheless, these studies do not allow for sellers bypassing the platform ("direct sales") or any other form of competition between platforms.

In contrast, Gans (2012) analyzes a framework where a single seller (content provider) can reach consumers (users of a mobile platform) both in an intermediated market and outside the marketplace. He finds that the platform provider cannot charge membership fees to consumers up front as he faces an unravelling problem. Imposing a most-favored customer clause may mitigate this problem, enabling the platform provider to charge positive membership fees to consumers.

\section{Payment card networks, interchange fees, and the no-surcharge rule (NSR)}

During the last decades, a considerable amount of studies focussed on the analysis of payment card networks. Although there are different network structures, all models share some basic features. When a consumer wants to purchase a product from a seller and it comes to paying, the consumer usually has (at least) two options: card or cash payment (assuming that the seller accepts and the consumer carries both means of payment). Both sellers and consumers may pay different kinds of fees to accept/carry and to use (debit or credit) cards. As the tariff systems of card networks typically comprise transaction-based components, sellers may have incentives to set prices based on the payment method used, discriminating between different means of payments by surcharging or granting discounts. However, card networks may impose no-surcharge or no-discrimination rules, prohibiting those practices 12

\footnotetext{
${ }^{11}$ Jullien 2012) offers a comprehensive up-to-date survey on two-sided (B2B) platforms, including a general introduction to two-sided markets.

${ }^{12}$ Legislation on the NSR considerably differs across countries. In the EU, imposing a NSR is prohibited: "The payment service provider shall not prevent the payee from requesting from the payer a charge or from offering him a reduction for the use of a given payment instrument." European Commission, 2007a, article 52(3), meanwhile implemented by all Member States). However, surcharging may be generally prohibited (NSR imposed by law) - this is the case in 10 states of the US and several countries in Europe (e.g. Austria, Italy, Sweden - facilitated by the Payment Services Directive which also states that "Member States may forbid or limit the right to request charges taking into account the need to encourage competition and promote the use of efficient payment instruments"). In most states of the US, card networks are free to impose a NSR.
} 
My work may be seen as a contribution to this strand of literature: sales channels correspond to different means of payment and the platform operator plays the role of a (unitary) card network, or, in case of a four party model, the role of an issuer who possesses market power and can set both buyer fees and the interchange fee which is passed through by competitive acquirers. In the following, I survey several models of payment card networks and some empirical insights on no-surcharge rules 13

As a precursor of the literature on two-sided markets, Rochet and Tirole (2002) discuss the interchange fee (i.e., the transaction-based payment between issuing and acquiring bank) in a four party credit card network. Acquiring banks are assumed to be perfectly competitive, setting the seller fee/discount equal to the sum of interchange fee and their per-transaction costs. Issuing banks have market power and set both the interchange fee and the consumer fee, playing the "balancing" platform role. Two sellers serve cardholders and non-cardholders, competing à la Hotelling and setting the same price to both customer groups. Under the no-surcharge rule, the interchange fee/seller discount is set equal to or above the efficient level, possibly leading to an overprovision of card payment services. Although the main analysis is conducted under the NSR, Rochet and Tirole argue that lifting the NSR would imply neutrality of the interchange fee (sellers simply pass costs through and price-discriminate) and would lead to an underprovision of card services. Consequently, the welfare implication of lifting the NSR is ambiguous. However, the network's decision on imposing a NSR remains unexplored.

Focussing on the potential neutrality of interchange fees, Gans and King (2003) explain that the interchange fee does not affect the market outcome under "payment separation", i.e., if sellers can perfectly price-discriminate between cash-paying consumers and card users, or if each seller only serves one of the two groups.

Langlet and Uhlenbrock (2011) analyze the determination of the seller fee under the NSR when consumers pay no fees. They assume that there are two distinct groups of fixed (exogenous) sizes: card users and cash-paying consumers. In a framework of differentiated Bertrand competition between two sellers, they analyze how the proportion of card users and demand parameters affect the optimal seller fee.

Bourreau and Verdier (2010) demonstrate that a payment platform may set a low interchange fee to deter a seller, who competes with another seller à la Hotelling, from bypassing the platform by issuing private cards. As the issuing seller can charge a fee for using her private card, they implicitly allow for price discrimination between users of the private card and all other customers (cash-paying or non-private card users). However, the second seller cannot price-discriminate in their framework, and the study does not offer a comparison between uniform pricing and surcharging/price discrimination.

Wright (2003) analyzes interchange fees and the adoption of a NSR based on the framework introduced by Rochet and Tirole (2002). However, Wright assumes that seller pricing is

\footnotetext{
${ }^{13}$ Verdier (2011) offers a good survey of the literature on interchange fees. The "Report on the retail banking sector inquiry" European Commission, 2007b) offers (empirical) insights into the European banking system, in particular card payment arrangements and interchange fees.
} 
either monopolistic or perfectly competitive. He finds that with a monopoly seller, the NSR is both profitable to the card association and socially desirable as it diminishes otherwise excessive surcharging by the seller and also limits the interchange fee that the seller is willing to accept to the efficient level. With perfect competition between sellers, both a social planner and the card network are indifferent between allowing sellers to price discriminate and imposing the NSR. Furthermore, the level of the interchange fee becomes irrelevant; under the NSR, sellers specialize on either cash-paying consumers or card users, setting their respective price equal to their perceived per-transaction costs.

Schwartz and Vincent (2006) analyze the NSR when a payment network faces a single monopoly seller. Unlike Wright (2003), Schwartz and Vincent take each consumer's payment mode as exogenously given (two groups of consumers with fixed sizes), but transaction quantities are variable (elastic demand). They find that under the NSR the payment network prefers a price structure with low consumer fees. In general, the payment network prefers the NSR, to the detriment of cash-paying customers and the seller. The overall effect on welfare depends on the proportion of card users relative to cash users, the feasibility of granting consumers rebates (charging negative fees), and the seller's benefit from card vs. cash transactions.

Economides and Henriques (2011) analyze the no-surcharge rule in a classic two-sided market framework, offering a microeconomic foundation of network effects. They allow for various forms of seller competition/market power by assuming that, without a NSR, the price of a good equals a linear combination of consumers' willingness to pay and seller's perceived marginal costs (seller fee minus individual benefit from card payment). Although this assumption seems fairly general, it may also cause some problems within the given framework: firstly, as their assumption rules out any "strategic" effects of card acceptance, sellers only accept cards if their per-transaction benefit exceeds the seller fee. Therefore, perceived marginal costs are negative in equilibrium and seller's surcharge for card payments is always negative, i.e., cash prices are higher than card prices. Secondly, prices may become negative if sellers have little market power and the absolute value of the perceived costs is high.

The empirical studies of Bolt, Jonker and van Renselaar 2010) and Jonker (2011) examine the surcharging behavior of Dutch retailers (NSRs are prohibited in the Netherlands) and the corresponding consumer responses. They find that about $20 \%$ of all sellers indeed price discriminate by surcharging card transactions. Jonker points out that sellers become more likely to accept card payments with increasing competition, while surcharges increase in their market power. However, it turns out that the majority of consumers tries to avoid surcharges either by choosing different means of payment or by visiting another store.

Altogether, although some studies on payment card networks provide insights into the effects caused by NSRs, most work focusses on the interchange fee. Despite some general theoretical analogies between NSRs and other across-platforms parity agreements, the work surveyed above presumes a specific industry structure. Furthermore, it includes several limitations. The studies most closely related to my work are Rochet and Tirole (2002), Wright 
(2003), and Schwartz and Vincent (2006). Rochet and Tirole do not focus on NSRs, and, hence, do not analyze the intermediary's decision to impose a NSR. Wright only allows for extreme forms of seller competition. Schwartz and Vincent analyze a framework without seller competition and with an exogenous split-up between card users and cash users, but allow for elastic demand.

\section{Outline}

The remainder of the paper is structured as follows: in section 2, I introduce the framework. In section 3, I solve the model backwards, comparing sellers' decisions with and without a no-discrimination rule, and analyzing the intermediary's decision on imposing a nodiscrimination rule. In section 4 , I discuss welfare implications of no-discrimination rules. Finally, I give a discussion in section 5 and some concluding remarks in section 6.

\section{Framework}

I consider a framework with three seller 14 who can become active in two sales channels: a platform (or marketplace) 15 provided by an intermediary, and a direct sales channel.

Each seller offers a single product (possibly using both channels). Products are horizontally differentiated: they are equidistantly located on the circumferences of two Salop circles 16 Each Salop circle represents one sales channel.

Sellers face linear production costs. The costs (not including platform fees) that both channels have in common are normalized to zero. I assume that sellers incur additional pertransaction costs for processing sales outside the platform; this cost difference parameter is denoted by $c 17$

The intermediary provides a platform and can charge sellers and buyers per-transaction fees if trade takes place in his marketplace. The seller fee is denoted by $f_{s}$, and the buyer fee is called $f_{b}$. The intermediary bears costs of $k$ for each transaction conducted over his platform.

Consumers apply a sequential decision rule. In a first step, they select their favorite product based on the prices observed in one of the two sales channel. In a second step, they buy one unit of the selected product, using the channel that yields the highest (individual) net utility.

I assume that consumers are heterogeneous in three independent dimensions. Firstly, they can be divided into two disjunct groups: a mass of $M_{d}$ consumers searches for products outside the platform and selects their favorite product based on prices in the direct sales channel (" $d$ "). The remaining mass, labeled $M_{m}$, chooses their respective favorite product

\footnotetext{
${ }^{14}$ I choose three sellers to allow for a tractable analysis of asymmetric scenarios with one seller specializing on a single sales channel.

${ }^{15}$ In the following, I use the terms "platform" and "marketplace" interchangeably.

${ }^{16}$ I use two circles to allow asymmetric scenarios with a different number of sellers in each channel. If all sellers are active in both channels, both circles are identical and, hence, one circle would suffice to describe horizontal product differentiation. For the basic model of a circular market, cf. Salop (1979).

${ }^{17}$ Note that this cost difference does not account for the seller fee introduced below.
} 
based on the prices which the sellers charge within the intermediary's marketplace (" $m$ "). Then, the assumption on sequential consumer decisions creates a spillover effect between channels: consumers search for products and learn about existence in their respective channel $i \in\{d, m\}$, but may buy in the other channel $j \in\{m, d\}, j \neq i$. This implies that (i) not selling in channel $i$ results in losing all potential buyers from group $i$ (mass $M_{i}$ is not aware of product/seller existence), and that (ii) it may be profitable to set a relatively low price in channel $i$ and a higher price in channel $j \neq i$, attracting consumers in channel $i$ who may finally buy in channel $j$ (if they like channel $j$ much better), or, cross-subsidizing between channels that differ in perceived costs.

Secondly, consumers differ in their attitude towards horizontal product characteristics: consumers choosing their favorite product in channel $i \in\{d, m\}$ are uniformly distributed on the circumference of the respective Salop circle for channel $i$. If a consumer who is located at $x$ buys from a seller who is located at $y$ on the circumference of the Salop circle that belongs to the consumer's channel, the consumer incurs quadratic transportation (or mismatch) costs of $t \cdot d(x, y)$, where

$$
d(x, y) \equiv \min \left\{(x-y)^{2},(1-|x-y|)^{2}\right\}
$$

equals the shortest quadratic distance between the consumer's and the seller's location 18 The parameter $t$ can be interpreted as a measure of sellers' market power.

Thirdly, consumers obtain heterogeneous benefits from using the platform instead of the direct sales channel 19 All consumers are assumed to have the same initial reservation value $r$ (before transportation costs) for buying a product in the direct sales channel. The additional benefits from platform usage may be positive or negative and are distributed according to a differentiable (cumulative) distribution function $F(v) 20$

Hence, the utility of a consumer who is located at $x$ and buys from a seller who is located at $y$ is given by

$$
r-p_{d}-t \cdot d(x, y)
$$

if he buys at a price of $p_{d}$, using the direct sales channel, or by

$$
r+v-p_{m}-t \cdot d(x, y)
$$

if he buys at a price of $p_{m}$ in the marketplace.

\section{Timing}

The timing is given as follows:

1. The intermediary decides on imposing a no-discrimination rule and sets corresponding per-transaction fees $f_{s}$ and $f_{b}$.

\footnotetext{
${ }^{18}$ While a linear distance function would also be feasible, the quadratic one ensures existence of pure-strategy equilibria in the pricing game also in asymmetric scenarios where one of the sellers serves a single sales channel.

${ }^{19}$ At least a certain degree of household heterogeneity seems reasonable. For empirical evidence on heterogeneous channel valuations of households, cf. e.g. Chintagunta, Chu and Cebollada (2012).

${ }^{20}$ As parts of the analysis require a concrete specification of this distribution, I later will assume that the additional benefits follow a uniform distribution with $k-c \in(\underline{v}, \bar{v})$, where $[\underline{v}, \bar{v}]$ denotes the support.
} 
2. Sellers' distribution and pricing decisions:

i) Sellers simultaneously choose in which channels to offer their products 21

ii) Sellers simultaneously set (channel-dependent) prices.

3. Consumers' sequential buying decisions:

i) Consumers decide which product to buy (based on prices in the channel that corresponds to their respective group $M_{i}, i \in\{d, m\}$ ).

ii) Consumers buy one unit of the chosen product, using the best sales channel.

The price that seller $k \in\{1,2,3\}$ charges in channel $i \in\{d, m\}$ will be denoted by $p_{k, i}$. If the intermediary imposes a no-discrimination rule, sellers are not allowed to discriminate between channels, i.e., each seller charges a uniform price $p_{k} 22$

I assume that sellers and the intermediary maximize their expected profits, i.e., they are risk neutral. Consumers maximize their individual surplus. All outside options are normalized to zero. In order to ensure existence of pure-strategy equilibria in (out-of-equilibrium) pricing subgames where one seller specializes on a single sales channel, I restrict the ratio between the ex-ante consumer masses: $\frac{M_{m}}{M_{d}} \in\left(\frac{1}{8}, 8\right)$.

\section{Analysis}

In the following, I solve the model introduced in the previous section for the case of a symmetric Nash equilibrium within the pricing subgame (all sellers being active in both sales channels). Within the analysis of stage 2, I examine sellers' pricing decisions, firstly without a no-discrimination rule, then under a no-discrimination rule. I show that no seller has an incentive to be active in only one channel without a no-discrimination rule under a mild regularity condition. If the intermediary imposes a no-discrimination rule, his tariff reflects the sellers' participation constraints. Finally, I analyze the intermediary's decision on imposing a no-discrimination rule.

\subsection{Consumers' sequential buying decisions}

\section{Decision on sales channel}

Given his individual additional utility $v$ from buying products on the platform, a consumer who selected seller $k$ 's product, $k \in\{1,2,3\}$, prefers buying outside the platform (i.e., in the direct channel) if

$$
r-p_{k, d} \geq r+v-f_{b}-p_{k, m}
$$

\footnotetext{
${ }^{21}$ During the following analysis, I focus on cases with all sellers being active in both sales channels, i.e., I ensure that a unilateral specialization on a single sales channel is not profitable to any seller.

${ }^{22}$ I abstract from monitoring problems and sellers' attempts not to comply with an imposed NDR as platform operators can easily observe sellers' prices in other (online) channels and, moreover, can invite/incentivize consumers to report non-conform seller behavior (examples include Amazon's “Tell us about a lower price” function and their "Price Check" app, or HRS's money-back guarantee).
} 
or, equivalently, if $v \leq f_{b}+p_{k, m}-p_{k, d}$. Hence, if a unit mass of consumers wants to buy product $k$ and the respective seller is active in both channels, a (expected) mass of

$$
\operatorname{Pr}\left(v \leq f_{b}+p_{k, m}-p_{k, d}\right)=F\left(f_{b}+p_{k, m}-p_{k, d}\right)
$$

buys outside. I presume full market coverage, i.e., $r$ being sufficiently high.

\section{Selection of favorite product}

Each consumer's selection of his respective favorite product within a given channel $i \in\{d, m\}$ follows the basic Salop model. Consumers' locations $x \in[0,1)$ are denoted by the length of the circumference between them and the location of seller 1's product, measured clockwise. Hence, the location of seller 1's product is defined as $x_{1}=0$, the location of seller 2's product is $x_{2}=\frac{1}{3}$, and seller 3's product is located at $x_{3}=\frac{2}{3}$.

Firstly, I analyze a situation of all three firms being active in channel $i$. A consumer belonging to mass $M_{i}, i \in\{d, m\}$, who is located at $x \in\left[0, \frac{1}{2}\right]$ is indifferent between seller 1's and seller 2's product if his location $x$ fulfills

$$
p_{1, i}+t \cdot x^{2}=p_{2, i}+t \cdot\left(\frac{1}{3}-x\right)^{2} \Leftrightarrow x=\frac{1}{6}+3 \cdot \frac{p_{2, i}-p_{1, i}}{2 t} .
$$

A consumer who is located at $x \in\left[\frac{1}{2}, 1\right)$ is indifferent between seller 1's and seller 3's product if his location $x$ fulfills

$$
p_{1, i}+t \cdot(1-x)^{2}=p_{3, i}+t \cdot\left(x-\frac{2}{3}\right)^{2} \Leftrightarrow x=\frac{5}{6}+3 \cdot \frac{p_{1, i}-p_{3, i}}{2 t} .
$$

Accordingly, given the price of seller $k$ and the prices of the two other sellers $l_{1}$ and $l_{2}$, a fraction of

$$
q_{k, i}\left(p_{1, i}, p_{2, i}, p_{3, i}\right)=\frac{1}{3}+3 \cdot \frac{p_{l_{1}, i}+p_{l_{2}, i}-2 \cdot p_{k, i}}{2 t}
$$

chooses the product of seller $k$.

If only two sellers, without loss of generality labeled 2 and 3, are active in channel $i$ and are equidistantly located on the respective circumference, it is straightforward to show that a fraction of

chooses the product of seller $k \neq l \underline{23}$

$$
q_{k, i}\left(p_{2, i}, p_{3, i}\right)=\frac{1}{2}+2 \cdot \frac{p_{l, i}-p_{k, i}}{t}
$$

\subsection{Sellers' distribution and pricing decisions}

\section{Pricing decisions under full participation without NDR}

If all sellers are active in both channels, the overall mass of consumers who buy from seller $k$ equals

$$
Q_{k}\left(\mathbf{p}_{\mathbf{d}}, \mathbf{p}_{\mathbf{m}}\right) \equiv M_{d} \cdot q_{k, d}\left(\mathbf{p}_{\mathbf{d}}\right)+M_{m} \cdot q_{k, m}\left(\mathbf{p}_{\mathbf{m}}\right),
$$

\footnotetext{
${ }^{23}$ If $k$ and $l$ are asymmetrically located on the circumference, the slope of $q_{k, i}$ changes; in particular, if they are located as in the case with three sellers (e.g. at $x_{k}=\frac{1}{3}$ and $x_{l}=\frac{2}{3}$ ), it follows $q_{k, i}\left(p_{k, i}, p_{l, i}\right)=\frac{1}{2}+\frac{9}{4} \cdot \frac{p_{l, i}-p_{k, i}}{t}$.
} 
with $\mathbf{p}_{\mathbf{i}} \equiv\left(p_{1, i}, p_{2, i}, p_{3, i}\right), i \in\{d, m\}$, defined as price vectors.

As the split-up between channels is determined by the sum of the buyer fee $f_{b}$ and the price difference $\Delta p_{k} \equiv p_{k, m}-p_{k, d}$, seller $k$ 's expected profit can be written as

$$
\pi_{k}\left(\mathbf{p}_{\mathbf{d}}, \mathbf{p}_{\mathbf{m}}\right) \equiv Q_{k}\left(\mathbf{p}_{\mathbf{d}}, \mathbf{p}_{\mathbf{m}}\right) \cdot\left\{F\left(f_{b}+\Delta p_{k}\right) \cdot\left(p_{k, d}-c\right)+\left(1-F\left(f_{b}+\Delta p_{k}\right)\right) \cdot\left(p_{k, m}-f_{s}\right)\right\} 24
$$

In a symmetric equilibrium with $p_{1, i}=p_{2, i}=p_{3, i}, i \in\{d, m\}$, the two first order conditions $\frac{\partial \pi_{k}}{\partial p_{k, i}}=0, i \in\{d, m\}$, imply 25

$$
\Delta p_{k}=f_{s}-c+\frac{\frac{M_{d}}{M_{d}+M_{m}}-F\left(f_{b}+\Delta p_{k}\right)}{f\left(f_{b}+\Delta p_{k}\right)} .
$$

This equation (implicitly) defines the equilibrium price difference $\Delta p_{k}$. Taking a closer look at the critical level of additional platform benefit $\widetilde{v} \equiv f_{b}+\Delta p_{k}$, I arrive at the following result:

Proposition 1 (No two-sidedness without NDR).

As long as sellers are active in both channels and are free to set different prices across channels, the allocation of consumers between both channels only depends on the overall fee $f_{b}+f_{s}$, but not on its split-up between sellers and buyers.

As the overall number of transactions is fixed (I assume that the willingness to pay $r$ is sufficiently high) and sellers fully internalize the impact of their decision on the division of sales between channels, the allocation of fees does not matter and the intermediary's fee structure features neutrality 26 Hence, restricting the analysis by an assumption on the distribution $F(\cdot)$ is without loss of generality regarding the (ambiguous) split-up of fees between sellers and buyers. However, it restricts the pass-through rate, i.e., how sellers react to a change of the overall fee. Nevertheless, I make the following assumption for the sake of tractability:

Assumption 1 (Additional platform benefits are uniformly distributed). Additional platform benefits follow a uniform distribution with support $[v, \bar{v}]$. The difference between intermediary's and seller's costs, $k-c$, is contained in this support 27

In the subsequent analysis, I refer to the respective cumulative uniform distribution function by $F_{u}$, and to the respective density function by $f_{u}$, indicating use of assumption 128

Given this assumption, equation (1) can be solved for $\Delta p_{k} 29$

$$
\Delta p_{k}=\frac{1}{2} \cdot\left(\frac{M_{d}}{M_{d}+M_{m}} \cdot(\bar{v}-\underline{v})+\underline{v}+f_{s}-f_{b}-c\right) .
$$

\footnotetext{
${ }^{24}$ I assume that the distribution represented by $F$ is such that all optimization problems are well-behaved. In particular, this is the case under assumption 1

${ }^{25}$ All derivations and proofs are relegated to the appendix.

${ }^{26}$ Note that this result is in line with previous literature, also cf. my literature review.

${ }^{27}$ The assumption $k-c \in(\underline{v}, \bar{v})$ ensures that neither of both sales channels is redundant from a social point of view. Note that the support may contain negative values. Hence, $k-c<0$ is not ruled out.

${ }^{28}$ Sellers' pricing decisions under a no-discrimination rule can be calculated without assumption 1 prices in absence of a no-discrimination rule and the intermediary's tariff decisions explicitly rely on this assumption.

${ }^{29}$ During the subsequent analysis, I assume that the difference $\left(f_{b}+f_{s}\right)-c$ is such that the indifferent consumer defined in 3 lies within $(\underline{v}, \bar{v})$. The optimal fees indeed fulfill this condition, cf. the analysis of stage 1 .
} 
This implies that the indifferent consumer between both channels is characterized by the critical level of additional platform benefit

$$
\widetilde{v}\left(f_{b}+f_{s}\right)=\frac{1}{2} \cdot\left(\frac{M_{d}}{M_{d}+M_{m}} \cdot(\bar{v}-\underline{v})+\underline{v}+\left(f_{b}+f_{s}\right)-c\right),
$$

which reconfirms the neutrality of the fee structure. Furthermore, as the critical level of additional utility from platform use is increasing in both fees, and, in particular, in the seller's perceived difference of transaction costs, $\left(f_{b}+f_{s}\right)-c$, less consumers use the platform if fees are increased or sellers face lower costs $c$. Moreover, the ex-ante distribution of consumers between channels affects the equilibrium split-up: the more consumers search for their favorite products on the platform, the larger the mass of platform buyers (for a given fee level). The latter fact reflects that sellers' incentives to set lower prices to attract consumers in a channel become stronger if the relative mass of consumers in this channel (who can be allured) increases. I will come back to this "channel importance" effect within the following discussion of sellers' pricing decisions.

Lemma 1 (Pricing without NDR under uniformly distributed platform benefits). Without a no-discrimination rule, if all sellers are active in both channels, prices are given by

$$
p_{k, m}^{*}=f_{s}+\frac{t}{9}+F_{u}\left(\widetilde{v}\left(f_{b}+f_{s}\right)\right) \cdot\left(\frac{M_{d}}{M_{d}+M_{m}}-\frac{f_{b}+f_{s}-c-\underline{v}}{\bar{v}-\underline{v}}\right) \cdot\left(\frac{\bar{v}-\underline{v}}{2}\right),
$$

and

$$
p_{k, d}^{*}=c+\frac{t}{9}-\left\{1-F_{u}\left(\widetilde{v}\left(f_{b}+f_{s}\right)\right)\right\} \cdot\left(\frac{M_{d}}{M_{d}+M_{m}}-\frac{f_{b}+f_{s}-c-\underline{v}}{\bar{v}-\underline{v}}\right) \cdot\left(\frac{\bar{v}-\underline{v}}{2}\right) .
$$

Note that these prices reflect both competition between sellers within each channel and competition across channels. The first two summands of each price equal the respective price that would arise in an independent market with three sellers, offering differentiated products and competing à la Salop. The third summand of each price captures how sellers internalize that the distribution of consumers between channels is affected by the price difference. If the ex-ante fraction of consumers in the direct sales channel, $\frac{M_{d}}{M_{d}+M_{m}}$, does not coincide with the relative split-up that would result just from the difference between the overall platform fee $f_{b}+f_{s}$ and outside costs $c$, prices differ from the basic prices $c+\frac{t}{9}$ and $f_{s}+\frac{t}{9}$, respectively:

Corollary 1 (Benchmark: independent-markets pricing). The prices defined by equations (4) and (5) coincide with the respective prices that would result in two independent markets with competition à la Salop if $\frac{M_{d}}{M_{d}+M_{m}}=\frac{f_{b}+f_{s}-c-\underline{v}}{\bar{v}-\underline{v}}$.

Corollary 2 (Benchmark: uniform pricing). Sellers voluntarily set uniform prices if $f_{s}-c=\left(\frac{f_{b}+f_{s}-c-\underline{v}}{\bar{v}-\underline{v}}-\frac{M_{d}}{M_{d}+M_{m}}\right) \cdot \frac{\bar{v}-\underline{v}}{2}$.

However, note that the level of $p_{k, m}$ is somewhat arbitrary as for any given overall fee $f_{b}+f_{s}$, every distribution of this overall fee on sellers and buyers results in the same payoffs for all agents. Furthermore, taking a closer look at prices, I find that the deviation from independent-markets pricing in fact constitutes a cross-subsidization between channels with no effect on the seller's overall profits: 
Proposition 2 (Cross-subsidization and seller's expected profits).

If all sellers are active in both channels, each seller's profit equals the sum of the basic Salop profits, $\left(M_{d}+M_{m}\right) \cdot \frac{t}{27}$. Hence, the loss from deviating from independent-markets pricing in one channel is compensated by the gains from the higher price in the other channel.

If the mass $M_{d}$ of consumers who choose their preferred product in the direct sales channel is relatively large, this amplifies the effect of a change in $\mathbf{p}_{\mathbf{d}}$ relative to the effect of a change in $\mathbf{p}_{\mathbf{m}}$. Hence, if the direct sales channel is relatively important for product choice, competition becomes (relatively) fiercer in this channel, but more relaxed in the platform channel, and vice versa. The combination of horizontal product differentiation with unit demand and uniformly distributed consumers implies that the two effects (lower prices in one channel, but higher prices in the other one) cancel out and overall profit equals the basic Salop profit.

Before turning to sellers' pricing decisions under a no-discrimination rule, I make the following (mild) assumption to ensure that specialization on a single sales channel is never profitable to a seller without a no-discrimination rule:

Assumption 2 (Differentiation parameters and ex-ante distribution of consumers). The ratio between the range of additional platform utilities, $(\bar{v}-\underline{v})$ (which measures heterogeneity of consumers' tastes regarding sales channels), and the transportation cost parameter $t$ (which captures differences in consumers' tastes regarding products) is relatively small, given the ex-ante distribution of consumers between channels represented by $\gamma \equiv \frac{M_{m}}{M_{d}}$ :

$$
\begin{aligned}
& \frac{\bar{v}-\underline{v}}{t} \leq(3+2 \gamma) \cdot \frac{(15+8 \gamma) \cdot \sqrt{1+\gamma}-(15+13 \gamma)}{18 \gamma^{2}}, \\
& \frac{\bar{v}-\underline{v}}{t} \leq(2+3 \gamma) \cdot \frac{(15 \gamma+8) \cdot \sqrt{\frac{1+\gamma}{\gamma}}-(15 \gamma+13)}{18} .
\end{aligned}
$$

Proposition 3 (Specialization on a single sales channel is not profitable without NDR). Without a no-discrimination rule, a (unilateral) specialization on a single sales channel is not profitable to a seller, given assumptions [1 and [2,

Note that assumption 2 consists of two sufficient conditions which ensure that specialization is not profitable to a seller 30 even under extreme fee levels that would maximize specialization incentives.

If a seller specialized on channel $i \in\{d, m\}$, this would relax competition in channel $j \in\{m, d\}, j \neq i$, and, hence, the remaining sellers would increase prices in this channel, indirectly increasing the overall price level and, in particular, prices in channel $i$. Specialization is most attractive if product differentiation is small, i.e., competition within channels is fierce,

\footnotetext{
${ }^{30}$ The upper bound for the ratio $\frac{\bar{v}-\underline{\underline{v}}}{t}$ in condition [6 takes its minimum value 1.21344 at $\gamma=1.50227$, and the upper bound in condition $(7)$ takes the same minimum value at $\gamma=1.50227^{-1}$.
} 
given differentiation between channels as measured by $(\bar{v}-\underline{v})$ and consumers' relative exante distribution on channels, captured by $\gamma$.

The effects of seller specialization under a no-discrimination rule are discussed below.

\section{Pricing decisions under full participation and NDR}

In this paragraph, I consider sellers' pricing decisions under a no-discrimination rule with all sellers being active in both channels. Seller $k$ 's profit, given the vector $\mathbf{p}=\left(p_{1}, p_{2}, p_{3}\right)$ of uniform prices, equals

$$
\pi_{k}(\mathbf{p}) \equiv Q_{k}(\mathbf{p}) \cdot\left\{p_{k}-F\left(f_{b}\right) \cdot c-\left(1-F\left(f_{b}\right)\right) \cdot f_{s}\right\}
$$

where the overall mass of consumers who buy from seller $k$ under uniform pricing equals

$$
Q_{k}(\mathbf{p}) \equiv\left(M_{d}+M_{m}\right) \cdot\left(\frac{1}{3}+3 \cdot \frac{p_{l_{1}}+p_{l_{2}}-2 \cdot p_{k}}{2 t}\right) .
$$

Accordingly, under uniform pricing, the split-up of consumers between channels only depends on the buyer fee $f_{b}$ and is not affected by sellers' pricing decisions (as $\Delta p_{k}=0$ ).

Proposition 4 (Pricing decisions and expected profits under NDR).

Under a no-discrimination rule, each seller sets a price of $\frac{t}{9}+F\left(f_{b}\right) \cdot c+\left(1-F\left(f_{b}\right)\right) \cdot f_{s}$ if all sellers are active in both channels. The corresponding profit is given by $\left(M_{d}+M_{m}\right) \cdot \frac{t}{27}$.

Sellers' prices reflect their average costs. Due to the mode of competition, the assumption on inelastic demand, and the linear structure (additive additional benefits from platform use in combination with sequential consumer decision), sellers' profits under a nodiscrimination rule with full participation equal the profits without no-discrimination rule, although sellers cannot price-discriminate.

\section{Pricing under NDR when one seller does not serve platform consumers}

In order to check when serving only the direct sales channel is profitable to a seller, I calculate the profit of a seller who specializes on this channel when the other sellers are active in both channels and a no-discrimination rule is imposed 31 Afterwards, I compare this profit with the equilibrium profit reported in proposition 4 deriving a seller participation constraint.

Suppose seller 1 does not offer her product in the marketplace. Then, her profit from serving only consumers in the direct sales channel is given by

$$
\pi_{1}(\mathbf{p})=M_{d} \cdot\left(\frac{1}{3}+3 \cdot \frac{p_{2}+p_{3}-2 \cdot p_{1}}{2 t}\right) \cdot\left(p_{1}-c\right) .
$$

\footnotetext{
${ }^{31}$ A specialization on platform sales would only be profitable if $f_{s}$ was below a threshold smaller than $c$ (cf. the condition derived in appendix, p. 34. Such a small fee would never be optimal for the intermediary as he would gain from higher fees (due to higher per-transaction revenues and a larger mass of potential customers in case the seller does not specialize on platform sales).
} 
The profit of seller 2 (who faces two competitors in the direct sales channel and only one competitor in the marketplace) reads 32

$$
\begin{aligned}
\pi_{2}(\mathbf{p})= & M_{d} \cdot\left(\frac{1}{3}+3 \cdot \frac{p_{1}+p_{3}-2 \cdot p_{2}}{2 t}\right) \cdot\left\{p_{2}-F\left(f_{b}\right) \cdot c-\left(1-F\left(f_{b}\right)\right) \cdot f_{s}\right\} \\
& +M_{m} \cdot\left(\frac{1}{2}+2 \cdot \frac{p_{3}-p_{2}}{t}\right) \cdot\left\{p_{2}-F\left(f_{b}\right) \cdot c-\left(1-F\left(f_{b}\right)\right) \cdot f_{s}\right\} .
\end{aligned}
$$

Defining

$$
\gamma \equiv \frac{M_{m}}{M_{d}}
$$

as the ratio between the masses of consumers in the marketplace and the direct sales channel, calculating sellers' best responses, and inserting them into each other leads to

$$
p_{1}^{d e v}=\left(1+\frac{5 \gamma}{15+8 \gamma}\right) \cdot \frac{t}{9}+c+\left(1-\frac{9+4 \gamma}{15+8 \gamma}\right) \cdot\left(1-F\left(f_{b}\right)\right) \cdot\left(f_{s}-c\right)
$$

and

$$
p_{2}^{d e v}=p_{3}^{d e v}=\left(1+\frac{10 \gamma}{15+8 \gamma}\right) \cdot \frac{t}{9}+c+\left(1-\frac{3}{15+8 \gamma}\right) \cdot\left(1-F\left(f_{b}\right)\right) \cdot\left(f_{s}-c\right) .
$$

These prices consist of a markup term and a weighted average of the respective seller's own (average) costs and the competitors' (average) costs. The markups can be understood as follows: when seller 1 specializes on one channel, this relaxes competition between sellers 2 and 3 in the other channel. Therefore, sellers 2 and 3 face incentives to set higher markups in the marketplace (compared to a situation where all three sellers are active in both channels). As they can only set uniform prices, this implies that sellers 2 and 3 set higher markups in both channels. In response, seller 1 also increases her markup, but to a lesser extent.

Comparing the profit of the specialized seller and the profit of a seller if all sellers are active in both channels, I arrive at the following result 33

Proposition 5 (Non-profitability of unilateral specialization on direct sales channel). When a no-discrimination rule is imposed and all other sellers are active in both channels, specialization on the direct sales channel is not profitable to a seller if

$$
\left(1-F\left(f_{b}\right)\right) \cdot\left(f_{s}-c\right) \leq \frac{t}{9} \cdot\left(\frac{(15+8 \gamma) \cdot \sqrt{1+\gamma}-(15+13 \gamma)}{2 \cdot(3+2 \gamma)}\right) .
$$

Note that the right-hand side of condition (11) is strictly positive for $\gamma>0$ and strictly increasing in $\gamma$. There are three effects that arise if the seller specializes on outside sales:

(i) Reduced mass of potential customers: the seller loses all (potential) customers who select their favorite product on the platform.

(ii) Less competitive pressure: due to relaxed competition within the platform, all prices include higher markups under specialization.

\footnotetext{
${ }^{32}$ This profit is calculated under the assumption that the distance between sellers 2 and 3 on the Salop circle that represents the platform equals $\frac{1}{2}$. The derivation for locations corresponding to the scenario with three sellers can be found in the appendix; my results are robust against changes in the locations of the remaining two sellers.

${ }^{33}$ Again, this result remains (qualitatively) unchanged when locations of sellers 2 and 3 in the platform channel correspond to their locations in the other channel, cf. p.34
} 
(iii) Cost savings: all consumers who choose the specialized seller's product buy directly from the seller. This reduces the seller's costs: without specialization, a fraction of $1-$ $F\left(f_{b}\right)$ would buy using the platform, creating additional costs for the seller of $f_{s}-c$ per transaction 34

Accordingly, specialization is only attractive if relatively few consumers select their favorite product on the platform ( $\gamma$ is small), if the transportation cost parameter $t$ is relatively small (fierce seller competition/weak product differentiation), or if the seller fee $f_{s}$ drastically exceeds the costs $c$ of a direct transaction.

\subsection{Intermediary's decision on fees and NDR}

In the following, I firstly derive the intermediary's profit-maximizing fee and the corresponding profit if he does not impose a no-discrimination rule. Secondly, I calculate the maximum profit he can achieve when imposing a no-discrimination rule, taking into account constraint (11) which ensures participation of all sellers in both channels. Finally, I analyze his decision on imposing a no-discrimination rule by comparing both profit levels (both calculated for the case of uniformly distributed additional platform benefits).

\section{Profit-maximizing fee level without NDR}

Given assumptions 1 1 and 2 without imposing a no-discrimination rule, all sellers are active in both channels, regardless of the fees set by the intermediary. The number of transactions conducted over the intermediary's platform equals $\left(M_{d}+M_{m}\right) \cdot\left\{1-F_{u}\left(\widetilde{v}\left(f_{b}+f_{s}\right)\right)\right\}$, with $\widetilde{v}\left(f_{b}+\right.$ $f_{s}$ ) as defined in (3) under the uniform distribution assumption. His profit comprises this transaction volume and his margin $f_{b}+f_{s}-k$, and it is given by

$$
\Pi_{0}\left(f_{b}, f_{s}\right)=\left(M_{d}+M_{m}\right) \cdot\left\{1-F_{u}\left(\widetilde{v}\left(f_{b}+f_{s}\right)\right)\right\} \cdot\left(f_{b}+f_{s}-k\right) .
$$

Bearing in mind proposition 1, i.e., the split-up of $f_{b}+f_{s}$ between buyers and sellers being arbitrary without a no-discrimination rule, I arrive at the following result:

Lemma 2 (Profit-maximizing fee level without NDR).

Without imposing a no-discrimination rule, the intermediary achieves a maximum profit of

$$
\Pi_{0}^{*}=(1+\gamma) \cdot M_{d} \cdot\left(\frac{\bar{v}-\underline{v}}{2}\right) \cdot\left\{1-\frac{1}{2} \cdot\left(F_{u}(k-c)+\frac{1}{1+\gamma}\right)\right\}^{2}
$$

by setting a fee level of $f_{b}+f_{s}=c+\underline{v}+\frac{(k-c)-\underline{v}}{2}+(\bar{v}-\underline{v}) \cdot\left(1-\frac{1}{2(1+\gamma)}\right)$.

The optimal fee level is increasing in (average) transaction costs, in both the level and the spread of additional utility from platform usage, and in the ratio $\gamma$ (defined in (8)) which can be interpreted as "importance" of the platform for product choice.

\footnotetext{
${ }^{34}$ In this verbal discussion, I implicitly assume that $f_{s}>c$. The optimal platform fee indeed exceeds $c$ if additional platform utilities are likely to be positive; otherwise $f_{s}-c$ can be negative, but relatively large compared to the level of (negative) additional platform utilities, cf. the subsequent analysis.
} 
Corollary 3 (Channel allocation without NDR).

When the intermediary does not impose a no-discrimination rule, the indifferent consumer between channels is given by

$$
\widetilde{v}_{0}=\underline{v}+\left\{\frac{1}{2}+\frac{1}{4} \cdot\left(\frac{1}{1+\gamma}\right)\right\} \cdot(\bar{v}-\underline{v})+\frac{(k-c)-\underline{v}}{4} .
$$

A fraction of $F_{u}\left(\widetilde{v}_{0}\right)=\frac{1}{2}+\frac{1}{4} \cdot \frac{1}{1+\gamma}+\frac{1}{4} \cdot \frac{(k-c)-\underline{v}}{\bar{v}-\underline{v}}$ of all consumers buys in the direct sales channel.

The fraction $1-F_{u}\left(\widetilde{v}_{0}\right)$ of consumers who buy in the marketplace is decreasing in the relative cost difference captured by $F_{u}(k-c)=\frac{(k-c)-\underline{v}}{\bar{v}-\underline{v}}$ and increasing in $\gamma$. The latter fact can be explained as follows: the larger $\gamma$, the lower sellers' platform prices (compared to prices in the direct sales channel), and, hence, the higher the fraction of consumers buying over the platform.

\section{Profit-maximizing fees under NDR}

If the intermediary imposes a no-discrimination rule, buyers' channel choices are not affected by the prices that sellers charge (assuming full market coverage). Consequently, the intermediary's profit with uniform prices and full seller participation reads

$$
\Pi_{1}\left(f_{s}, f_{b}\right)=\left(M_{d}+M_{m}\right) \cdot\left(1-F_{u}\left(f_{b}\right)\right) \cdot\left(f_{b}+f_{s}-k\right) .
$$

Lemma 3 (Profit-maximizing fees under NDR and full seller participation).

When imposing a no-discrimination rule, the intermediary can achieve a profit of

$$
\Pi_{1}^{*}=(1+\gamma) \cdot M_{d} \cdot\left(\frac{\bar{v}-\underline{v}}{2}\right) \cdot\left\{\frac{t}{\bar{v}-\underline{v}} \cdot\left(\frac{(15+8 \gamma) \cdot \sqrt{1+\gamma}-(15+13 \gamma)}{9 \cdot(3+2 \gamma)}\right)+\frac{1}{2} \cdot\left(1-F_{u}(k-c)\right)^{2}\right\}
$$

by setting a buyer fee of

$$
f_{b}^{*}=\frac{k-c}{2}+\frac{\bar{v}}{2}
$$

and a seller fee of

$$
f_{s}^{*}=c+\frac{t}{9} \cdot\left(\frac{(15+8 \gamma) \cdot \sqrt{1+\gamma}-(15+13 \gamma)}{2 \cdot(3+2 \gamma) \cdot\left(1-F\left(f_{b}^{*}\right)\right)}\right)
$$

The intermediary sets his seller fee $f_{s}$ such that constraint (11) binds 35 while the buyer fee $f_{b}$ is set to achieve the profit-maximizing split-up of buyers between channels.

Corollary 4 (Channel allocation under NDR).

When the intermediary imposes a no-discrimination rule, the indifferent consumer between channels is given by $\widetilde{v}_{1}=f_{b}^{*}$ as defined in (16). Consequently, a fraction of $F_{u}\left(\widetilde{v}_{1}\right)=\frac{1}{2}+\frac{1}{2} \cdot \frac{(k-c)-\underline{v}}{\bar{v}-\underline{v}}$ of all consumers buys in the direct sales channel.

If the intermediary imposes a no-discrimination rule, the fraction $1-F_{u}\left(\widetilde{v}_{1}\right)$ of consumers who buy in the marketplace only depends on the distribution of additional platform benefits

\footnotetext{
${ }^{35}$ Note that the intermediary's profit is increasing in $f_{s}$ as long as all sellers remain active on the platform, cf. equation [14]. I focus on symmetric outcomes with all sellers being active on the platform.
} 
and the cost difference $k-c$. Again, it is decreasing in the (relative) cost difference $F_{u}(k-c)=$ $\frac{(k-c)-\underline{v}}{\bar{v}-\underline{v}}$ (i.e., in particular, decreasing in the intermediary's costs $k$ and increasing in sellers' costs $c$ ). However, the split-up does not depend on $\gamma$ as the effect of the ex-ante consumer distribution is absorbed by the seller fee $f_{s}^{*}$ but does not enter $f_{b}^{*}$.

\section{Intermediary's decision on imposing a NDR}

Comparing profits (12) and (15), I can state the following result:

Proposition 6 (Profitability of imposing a NDR).

The intermediary decides to impose a no-discrimination rule if

$$
\frac{t}{\bar{v}-\underline{v}} \cdot\left(\frac{(15+8 \gamma) \cdot \sqrt{1+\gamma}-(15+13 \gamma)}{9 \cdot(3+2 \gamma)}\right)>\left\{1-\frac{1}{2} \cdot\left(F_{u}(k-c)+\frac{1}{1+\gamma}\right)\right\}^{2}-\frac{1}{2} \cdot\left(1-F_{u}(k-c)\right)^{2} .
$$

Condition (18) comprises three factors that influence the profitability of imposing a nodiscrimination rule:

(i) the ratio between product differentiation parameter $t$ (as an inverse measure of seller competition) and spread of additional platform benefits $\bar{v}-\underline{v}$ (as a measure of channel differentiation),

(ii) the relative cost difference $F_{u}(k-c)$ (difference in per-transaction costs relative to consumers' additional platform benefits),

(iii) the initial split-up of consumers on sales channels $\gamma$ (as a measure of importance of the platform for product choice).

An increase in the first factor, $\frac{t}{\bar{v}-\underline{v}}$, makes imposing a no-discrimination rule relatively more profitable: if sellers face weaker competition (i.e., a higher level of $t$ ), the equilibrium splitup of consumers on sales channels, and, moreover, the intermediary's profit without a nodiscrimination rule remain unchanged. However, an increase in $t$ diminishes sellers' specialization incentives, relaxing their participation constraint, and, thereby, increasing the intermediary's profit under a no-discrimination rule 36

An increase in the second factor, $F_{u}(k-c)$, always results in lower platform profits. However, the profit under a no-discrimination rule and the profit without a no-discrimination rule are affected to different extents, changing the difference between them, and, hence, attractiveness of imposing a no-discrimination rule. More specifically, the intermediary's margin in equilibrium responds in the same way, regardless of his decision on a no-discrimination rule, but the channel split-up (characterized by the indifferent consumer) is less sensitive to a change in costs in absence of a no-discrimination rule as the price difference $\Delta p_{k}$ implies a lower pass-through rate. Since sellers' prices are also driven by the "channel importance" effect (without a no-discrimination rule), the overall effect of a change in $F_{u}(k-c)$ depends on $\gamma$ : if $\gamma$ and $F_{u}(k-c)$ are small, an increase in $F_{u}(k-c)$ makes imposing a no-discrimination

\footnotetext{
${ }^{36}$ Note that I consider a change in this factor solely due to a change in $t$. A change in $\bar{v}-\underline{v}$ affects $F_{u}(k-c)$, too.
} 
rule less attractive, while for high levels of $F_{u}(k-c)$ and/or $\gamma$, an increase in the relative cost difference makes imposing a no-discrimination rule more attractive 37

The effect of the third factor, the ratio between the initial mass of platform consumers and consumers in the direct sales channel, is driven by two forces: under a no-discrimination rule, $\gamma$ limits the seller fee, while without a no-discrimination rule, $\gamma$ distorts the price difference since it determines (relative) competitive pressure within each channel. While the left-hand side of condition (18) is only "slightly" concave (i.e., close to linear) in $\gamma$, the right-hand side has a more concave shape. Depending on the first two factors, two scenarios can be distinguished:

(a) Imposing a no-discrimination rule is profitable regardless of the level of $\gamma$ - this is the case if $t$ is relatively large (weak seller competition) and/or $F_{u}(k-c)$ takes an extreme level (in particular, if the intermediary faces relatively high costs).

(b) Imposing a no-discrimination rule is profitable only for extreme (i.e., low or high) levels of $\gamma$-this is the case if $t$ is relatively small and $F_{u}(k-c)$ does not take extreme levels (in particular, $F_{u}(k-c)$ not close to 1$) 38$

Taking a closer look at the intermediary's profits, the impact of the parameter $\gamma$ can be understood as follows: on the one hand, without a no-discrimination rule, sellers' prices in the direct sales channel are relatively low (compared to prices in the marketplace) for small levels of $\gamma$ as in these cases the direct sales channel is (relatively) more important for consumers' product choice. Therefore, only few consumers buy using the platform channel because of the large price difference $\Delta p_{k}=p_{k, m}-p_{k, d}$ that arises if $\gamma$ is small. Accordingly, the intermediary's profit without a no-discrimination rule is increasing in $\gamma$, and an increase in $\gamma$ makes imposing a no-discrimination rule less attractive. On the other hand, an increase in $\gamma$ diminishes sellers' specialization incentives, relaxing the participation constraint that limits the intermediary's seller fee when he imposes a no-discrimination rule. Therefore, an increase in $\gamma$ also leads to an increase in the intermediary's profit under a no-discrimination rule, and imposing a no-discrimination rule becomes more attractive.

For very small levels of $\gamma$ (i.e., $M_{d} \gg M_{m}$ ), imposing a no-discrimination rule, balancing the equilibrium channel split-up despite a very skewed initial split-up of consumers on sales channels, is very attractive. When increasing $\gamma$ (starting from a small level), the first effect (increase in profit without no-discrimination rule) dominates, and, hence, imposing a no-discrimination rule becomes less attractive for intermediate values of $\gamma$ (i.e., $M_{d} \approx M_{m}$ ). However, for larger values of $\gamma$ (i.e., $M_{d} \ll M_{m}$ ), the second effect (increase in profit under nodiscrimination rule due to relaxed participation constraint) dominates, and imposing a nodiscrimination rule becomes more attractive again. In particular, scenario (b) demonstrates that both forces can be decisive.

\footnotetext{
${ }^{37}$ Formally, the right-hand side of condition $(18)$ is increasing in $F_{u}(k-c)$ if $F_{u}(k-c)<\frac{1}{1+\gamma}$, and decreasing in $F_{u}(k-c)$ otherwise.

${ }^{38}$ For example, for the parameter constellation $\bar{v}-\underline{v}=1, t=1, F_{u}(k-c)=0.5$, imposing a no-discrimination rule is profitable if $\gamma<0.5067$ or $\gamma>2.3614$, also cf. figure 1
} 

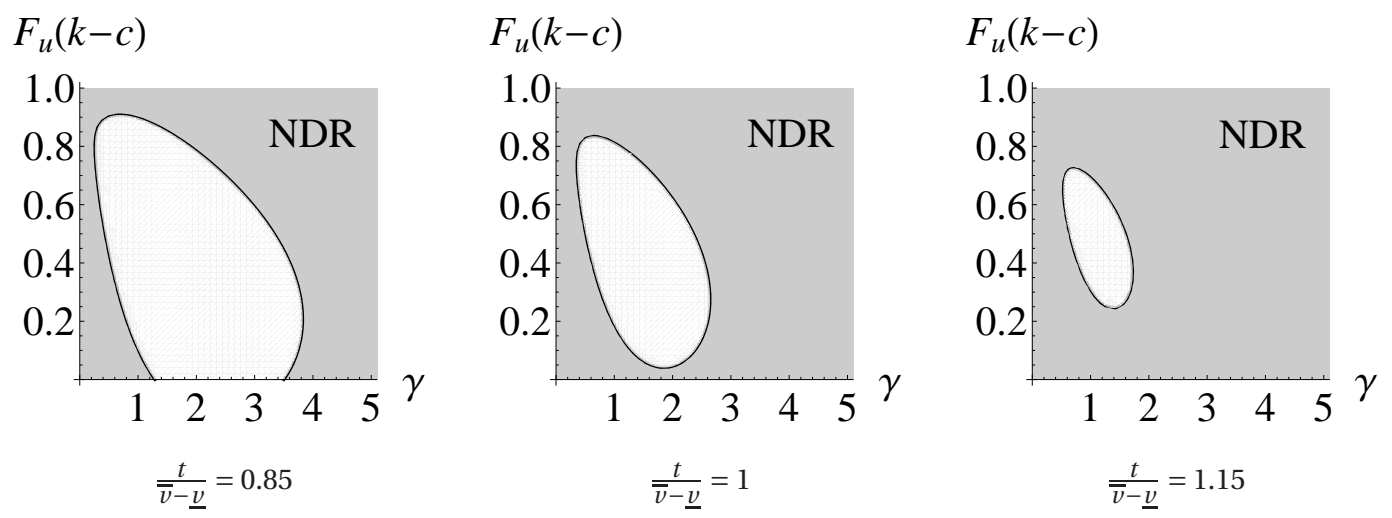

Figure 1: Profitability of imposing a no-discrimination rule for different ratios of $\frac{t}{\bar{v}-\underline{v}}$

Focussing on scenario (b), figure 1 illustrates under which combinations of the second factor $F_{u}(k-c)$ and the third factor $\gamma$ the intermediary imposes a no-discrimination rule for different levels of the differentiation ratio $\frac{t}{\bar{v}-\underline{v}}$ : for all parameter constellations within the shaded regions (i.e., outside the convex white regions), the intermediary prefers to impose a no-discrimination rule.

\section{Welfare implications}

I now turn to the welfare implications of imposing a no-discrimination rule. I illustrate that under certain parameter constellations, the intermediary imposes a no-discrimination rule, matching the socially desirable outcome (regarding the no-discrimination rule). However, under different parameter constellations, a ban on no-discrimination rules would increase welfare.

Social welfare comprises the intermediary's profit, sellers' profits, and consumer surplus. Firstly, the intermediary imposes a no-discrimination rule only if this is profitable to him. Secondly, with all sellers remaining active on the platform under a no-discrimination rule, sellers' profits are constant, irrespective of the intermediary's actual decision on imposing a no-discrimination rule. Therefore, within the given analysis, industry profits never decrease if the intermediary decides to impose a no-discrimination rule.

If the split-up of consumers between channels did not change when imposing a nodiscrimination rule, the intermediary would gain solely to the detriment of consumers. As all consumers' gross utilities would remain unchanged, social welfare would remain constant. However, the indifferent consumer between the two channels is determined endogenously and usually differs between both scenarios (no-discrimination rule imposed/not imposed). Hence, given the assumption of markets being fully covered, the allocation of consumers on channels determines the overall effect on welfare.

Lemma 4 (First-best outcome).

The welfare-maximizing outcome is characterized by the indifferent consumer $\widetilde{v}^{*}=k-c$. 
From a social point of view, consumers should buy using the platform channel if and only if their additional benefit from platform use covers the cost difference $k-c$.

Comparing the channel allocation in the first-best outcome with the allocation under a no-discrimination rule (given by corollary 4 ), I can state the following result:

Corollary 5 (Underuse of platform channel under NDR).

Under a no-discrimination rule, the platform channel is underused, i.e., $1-F_{u}\left(\widetilde{v}^{*}\right)>1-F_{u}\left(\widetilde{v}_{1}\right)$.

This result follows directly from the assumption that $k-c \in(\underline{\nu}, \bar{v})$ and is due to the monopoly inefficiency which is reflected in the profit-maximizing buyer fee $f_{b}^{*}$ given in (16).

Without a no-discrimination rule, there may be an overuse or an underuse of the platform channel:

Corollary 6 (Platform use without NDR). In absence of a no-discrimination rule, the platform channel is underused if and only if

$$
F_{u}\left(\widetilde{v}^{*}\right)<\frac{2}{3}+\frac{1}{3} \cdot\left(\frac{M_{d}}{M_{d}+M_{m}}\right) .
$$

Conversely speaking, without a no-discrimination rule, the platform is overused in case of a very high cost difference $k-c$ (which equals $\widetilde{v}^{*}$ ) and a large initial fraction of platform consumers (captured by $\gamma=\frac{M_{m}}{M_{d}}$ ). In this (extreme) case, the channel importance effect (i.e., sellers distorting platform prices downwards due to a high $\gamma$ ) overcompensates the effect caused by the platform's monopoly markup (which only partially internalizes the former effect). Under all other (less extreme) parameter constellations, the mass of consumers who buy in the direct sales channel given by corollary 3 is excessive and the platform is underused also in absence of a no-discrimination rule.

Focussing on the latter cases, I find that this underuse problem may be more severe than under a no-discrimination rule, depending on the cost difference $k-c$ and the initial split-up of consumers on their "native" sales channels:

Proposition 7 (Imposing a NDR increases social welfare). Imposing a no-discrimination rule results in more consumers buying in the platform channel, and, hence, in an increase in social welfare if $F_{u}\left(\widetilde{v}^{*}\right)<\frac{M_{d}}{M_{d}+M_{m}}$.

In absence of a no-discrimination rule, the intermediary's optimal fee level only partially offsets the channel importance effect on final prices. Consequently, sellers' discriminating prices reflect this effect and the equilibrium split-up of consumers on channels depends on the initial channel distribution. In constrast, under a no-discrimination rule, the equilibrium split-up of consumers on channels is solely determined by the buyer fee set by the intermediary and reflects his monopoly power, but it does not depend on the initial channel split-up of consumers.

For large initial fractions of consumers in the direct sales channels, platform prices substantially exceed prices in the direct sales channel (in absence of a no-discrimination rule), leading to little platform usage. Imposing a no-discrimination rule eliminates this inefficient 
price distortion. If the ex-ante fraction of consumers in the direct sales channel exceeds the first-best fraction $F_{u}\left(\widetilde{v}^{*}\right)$, this positive effect dominates the additional monopoly inefficiency, resulting in a more efficient channel split-up and higher welfare.

Connecting this result and the discussion of proposition 18, it is easy to construct both cases in which the intermediary profitably imposes a non-desirable no-discrimination rule, and cases in which the intermediary imposes a no-discrimination rule with a positive effect on social welfare. In particular, imposing a no-discrimination rule is both profitable to the intermediary and desirable from a social point of view if seller competition is very weak (i.e., $t \gg \bar{v}-\underline{v}$ ) while the intermediary's relative cost advantage is relatively large (i.e., $F_{u}(k-c)$ is small). Similarly, a no-discrimination rule can be profitable and lead to more platform use for intermediate levels of $F_{u}(k-c)$ if only few consumers select their favorite product on the platform (cf. scenario (b) from profitability discussion in previous section).

In contrast, a ban on no-discrimination rules would be desirable if the platform is very important for product choice (high level of $\gamma$ ) while the intermediary faces a (mild) relative cost disadvantage (e.g. $F_{u}(k-c)=\frac{2}{3}$ ). In this case, the intermediary imposes a nodiscrimination rule and sets a relatively high buyer fee, resulting in poor platform usage. If the intermediary could not restrict pricing, he would set a relatively high fee level, but the strong channel importance effect would drive sellers' platform prices down, reducing the price difference $\Delta p_{k}$ and leading to more platform usage than under a no-discrimination rule.

\section{Discussion}

As pointed out in the introduction, several prominent intermediaries impose nodiscrimination rules, restricting sellers' pricing decisions. However, before identifying conditions under which an intermediary profits from imposing a no-discrimination rule, and before discussing possible implications on welfare, it is necessary to understand why sellers may want to set different prices across sales channels in the first place.

Given the framework introduced above, without a no-discrimination rule, sellers' prices firstly reflect the difference between platform fees and per-transaction costs in the direct sales channel. Secondly, the relative importance of channels for consumers' product choice, determined by the ex-ante distribution of consumers on sales channels, leads to pricing distortions whose extent depends on the degree of channel differentiation. For very skewed initial consumer distributions, prices in the channel in which most consumers decide which product to buy are lower than the respective "independent markets" price, while consumers in the other channel face a higher price level. Thirdly, prices would be affected if seller specialization on sales channels arose. However, under assumption 2 , specialization on a single sales channel is never profitable without a no-discrimination rule as product differentiation (measured by $t$ ) is relatively large compared to channel differentiation (measured by $\bar{v}-\underline{v}$ ).

Accordingly, if the intermediary does not restrict sellers' pricing decisions, the equilibrium split-up of consumers on sales channels is determined by the difference between the 
overall fee level and per-transaction costs, channel differentiation, and the initial distribution of consumers on channels. In particular, the intermediary has no direct control over the allocation of consumers on channels.

In contrast, if the intermediary imposes a no-discrimination rule, the channel split-up no longer depends on the price difference between channels (which would reflect the overall fee), but only on the buyer fee. Therefore, imposing a no-discrimination rule results in the intermediary having more control. However, as sellers now cannot set (relatively) higher prices in the platform channel in response to a high seller fee, consumers do not internalize the differences in sellers' (channel-dependent) per-transaction expenditures when deciding in which channel to buy their preferred product. Consequently, sellers face stronger specialization incentives, which limit the fee the intermediary can charge.

Taken together, the intermediary prefers to control the split-up of consumers on sales channels directly by imposing a no-discrimination rule if (i) the market is characterized by a parameter constellation that results in an unfavorable equilibrium split-up of consumers on sales channels (from the intermediary's point of view), and (ii) the "costs" due to the seller participation constraint do not exceed the benefit from the improvement of the split-up on channels 39

In particular, imposing a no-discrimination rule is most attractive if the initial distribution of consumers is strongly skewed: with a very small initial fraction of platform consumers, only few consumers buy in the platform channel due to the substantial price difference $\Delta p_{k}$, and imposing a no-discrimination rule results in more platform usage. In contrast, if most consumers select their preferred product on the platform, sellers' specialization incentives are weak and the intermediary can charge high seller fees under a no-discrimination rule (while reducing the number of platform transactions directly by charging a high buyer fee).

If the intermediary faces a relatively strong cost disadvantage (i.e., his per-transaction costs are high compared to the costs that a seller bears when selling in the direct sales channel), again, imposing a no-discrimination rule is more profitable: less transactions are conducted over the platform, but the intermediary gains due to a higher fee level.

In the latter case, a ban on no-discrimination rules is likely to be welfare-enhancing as it results in more platform usage, which improves the allocation of consumers on sales channels (except for very extreme cases in which non-restricted pricing results in a relatively strong overuse of the platform channel). However, although no-discrimination rules always lead to an underuse of the platform channel (compared to the first-best usage level), platform usage can still be lower without a no-discrimination rule, and imposing a no-discrimination rule is welfare-enhancing under certain conditions.

\footnotetext{
${ }^{39}$ Note that the "costs" due to the limited seller fee can also become negative if product differentiation (measured by $t$ ) and/or platform importance, i.e., $\gamma$, is large, meaning that the intermediary can extract a larger part of the sellers' profits under a no-discrimination rule.
} 


\section{Concluding remarks and outlook}

By analyzing a framework in which competing sellers can reach consumers through different channels, this study yields insights into sellers' pricing behavior and the division of sales between channels. Furthermore, it allows the examination of the tariff decision of a platform provider and its impact on market outcomes. In particular, both profitability and efficiency of no-discrimination rules are discussed.

Depending on several factors (importance of the platform for product choice, sellers' market power, channel differentiation, and cost differences), the platform operator decides in favor of or against imposing a no-discrimination rule. As the effect of a no-discrimination rule on efficiency (desirable split-up of consumers between channels) may be positive or negative, both parameter constellations under which the platform operator's decision to impose a no-discrimination rule matches the socially desirable outcome and constellations where it fails to match the welfare-maximizing outcome can be identified.

As Aguzzoni et al. (2012) indicate, so far there has not been any study explicitly analyzing no-discrimination rules (or, more generally, third-party price relationship agreements) in intermediated markets. Although parts of the substantial work on payment card networks exhibit certain theoretical analogies with the framework introduced in this study, that literature focusses on a different industry structure. Even when abstracting from the additional "bank level" intermediation, the studies on no-surcharge rules show certain limitations that restrict applicability on the cases mentioned in the introduction. In contrast to the studies of Wright (2003) and Schwartz and Vincent 2006), my framework allows for imperfect merchant competition and accounts for the spillover effect whose presence seems reasonable in a multi-channel sales frameworl 40 and impacts both specialization incentives and price levels.

Although this study may also be seen as an extension to the literature on no-surcharge rules imposed by payment card networks, the main contribution is the provision of a framework that fosters the ongoing debate about the effects of across-platforms parity agreements (also called most-favored treatment clauses or no-discrimination rules) on the use of different trade opportunities. In particular, it sheds light on the restrictions which several prominent platform operators (e.g. HRS, Booking.com, Amazon) use and which recently became subjects of litigation.

However, this study only constitutes a first step towards a better understanding of such practices and abstracts from several aspects which may also affect outcomes in intermediated markets. Firstly, in this study, existence of a direct sales channel introduces competition between channels, but excludes strategic interactions between multiple platform operators. Future research could introduce a second intermediary, analyzing the effects on potential

\footnotetext{
${ }^{40}$ The spillover (or "billboard") effect, i.e., being active in one channel affects sales in the other channel due to consumers' endogenous decision where to buy their preferred product, has been documented at least for the hotel industry (cf. fn. 6]. Furthermore, it has also been used as an argument within the opinion of the Higher Regional Court Duesseldorf (file no. 33 O 16/12) on HRS's practices.
} 
competition (foreclosure effect of across-platforms parity agreements) or on actual competition between two established platform operators. Secondly, if platform operators face investment costs to establish their platforms or incur fixed costs to maintain or improve their platform services, imposing a no-discrimination rule may also be seen as a means to mitigate free-riding: without a restriction on sellers' pricing decisions, consumers utilize platform services to find their preferred product, but may buy in another (cheaper) channel which does not offer any service. This problem may lead to an underprovision of desirable services or, more generally, a lack of investment incentives. If the intermediary gains from a certain (desirable) investment under a no-discrimination rule, but cannot recover his investment costs without imposing a pricing restriction, prohibiting such restrictive practices may result in an inefficiently low investment level. Thirdly, future research could extent this framework by allowing for different types of platform fees. On the one hand, charging membership fees to consumers seems to be a (theoretical) option, in particular, as these may mitigate potential free-riding problems. However, none of the platform operators mentioned in the discussion so far charges consumers non-zero membership fees, and charging membership fees may not be feasible due to several reasons (e.g. consumers being uncertain about the individual benefits of platform services or commitment issues). On the other hand, future work could include proportional fees (i.e., royalties based on revenues) as these may induce additional effects of no-discrimination rules on platform profits. In particular, with per-transaction fees, the platform operator usually gains from cross-subsidization between channels as this leads to more transactions on his platform. However, if sellers cross-subsidizing leads to lower prices on the platform, the effect on platform profits may be less clear under proportional fees.

\section{Appendix}

\section{Background: HRS's most-favored treatment clause}

HRS's best-price guarantee/most-favored treatment clause (HRS.com, 2012):

"In principle, HRS expects its partner hotels to offer it the lowest room rates available. The Hotel guarantees that the HRS price is at parity with or lower than the lowest rate available for the Hotel on other reservation and travel platforms on the Internet or on offer on the Hotel's own Web pages."

As reactions on HRS's attempt to extend this most-favored treatment clause on prices at the reception desk and warning non-complying hotels, the German Cartel Office started an investigation (cf.Bundeskartellamt, 2012), and the Higher Regional Court Duesseldorf issued an injunction against warning letters that base on the extended version (file no. $33 \mathrm{O}$ 16/12).

\section{Background: Amazon's price parity rule}

In the EU, Amazon introduced a price parity rule in May 2010 (Amazon.co.uk, 2011): 
“(...) since 1st May, we are asking sellers who choose to sell their products on Amazon.co.uk not to charge customers higher prices on Amazon than they charge customers elsewhere. Accordingly, sellers selling under the Amazon.co.uk marketplace Participation Agreement need to comply with price parity requirements as set forth below.

Price parity for these sellers generally means that the item price and total price (total amount payable, including delivery charges but excluding taxes) of each product offered on Amazon.co.uk must not be higher than the corresponding prices at which the seller or its affiliates offers the product on other non-physical sales channels. This general requirement already applies to certain product categories in the Amazon.co.uk, Amazon.fr, and Amazon.de marketplaces, and has applied to the US marketplace for several years."

As a direct reaction, many sellers announced that they would no longer sell on Amazon under a price parity rule. Furthermore, after an injuction against Amazon's price parity, issued by the District Court of Munich (file no. 37 O 7636/10), used books have been exempted from the price parity rule in Germany. According to several reports in the business press, there has also been a general investigation by the German Cartel Office (Bundeskartellamt).

In response to a parliamentary question on concerns about Amazon's price parity rule, the European Commission stated (Wills, 2010):

"The Commission wishes to inform the Honourable Member that the Commission follows very closely the developments in the market for the online sales of books and is aware of Amazon's price policy.

As regards compliance with competition rules, Article 101 TFEU prohibits anticompetitive agreements between two or more companies. In this case, it concerns a unilateral decision taken by Amazon. Therefore, it appears that Article 101 is not applicable. Article 102 TFEU prohibits companies with a dominant market position from abusing their position. However, the Commission has not assessed whether Amazon has a dominant position. The Commission is hence not in a position at this stage to take a view on whether or not Amazon's price policy is in line with EU competition rules."

\section{Derivations \& Proofs}

\section{Pricing decisions under full participation without NDR, proof of proposition 1}

The derivatives of seller $k$ 's profit

$$
Q_{k}\left(\mathbf{p}_{\mathbf{d}}, \mathbf{p}_{\mathbf{m}}\right) \cdot\left\{F\left(f_{b}+\Delta p_{k}\right) \cdot\left(p_{k, d}-c\right)+\left(1-F\left(f_{b}+\Delta p_{k}\right)\right) \cdot\left(p_{k, m}-f_{s}\right)\right\}
$$

with respect to $p_{k, d}$ and $p_{k, m}$ read

$$
\begin{aligned}
\frac{\partial \pi_{k}}{\partial p_{k, d}}= & \left.\left\{F\left(f_{b}+\Delta p_{k}\right)+f\left(f_{b}+\Delta p_{k}\right)\left(\Delta p_{k}-f_{s}+c\right)\right)\right\} \\
& \times\left\{M_{m}\left(\frac{1}{3}+3 \frac{p_{l_{1}, m}+p_{l_{2}, m}-2 p_{k, m}}{2 t}\right)+M_{d}\left(\frac{1}{3}+3 \frac{p_{l_{1}, d}+p_{l_{2}, d}-2 p_{k, d}}{2 t}\right)\right\} \\
& -\frac{3 M_{d}}{t}\left\{F\left(f_{b}+\Delta p_{k}\right)\left(p_{k, d}-c\right)+\left(1-F\left(f_{b}+\Delta p_{k}\right)\right)\left(p_{k, m}-f_{s}\right)\right\}
\end{aligned}
$$


and

$$
\begin{aligned}
\frac{\partial \pi_{k}}{\partial p_{k, m}}= & \left.\left\{1-F\left(f_{b}+\Delta p_{k}\right)-f\left(f_{b}+\Delta p_{k}\right)\left(\Delta p_{k}-f_{s}+c\right)\right)\right\} \\
& \times\left\{M_{m}\left(\frac{1}{3}+3 \frac{p_{l_{1}, m}+p_{l_{2}, m}-2 p_{k, m}}{2 t}\right)+M_{d}\left(\frac{1}{3}+3 \frac{p_{l_{1}, d}+p_{l_{2}, d}-2 p_{k, d}}{2 t}\right)\right\} \\
& -\frac{3 M_{m}}{t}\left\{F\left(f_{b}+\Delta p_{k}\right)\left(p_{k, d}-c\right)+\left(1-F\left(f_{b}+\Delta p_{k}\right)\right)\left(p_{k, m}-f_{s}\right)\right\} .
\end{aligned}
$$

In a symmetric equilibrium with $p_{k, i}=p_{l, i}$, the first order conditions become

$$
\begin{aligned}
& \left\{F\left(f_{b}+\Delta p_{k}\right)+f\left(f_{b}+\Delta p_{k}\right)\left(\Delta p_{k}-f_{s}+c\right)\right\} \times\left\{M_{m}+M_{d}\right\} \\
= & 9 \frac{M_{d}}{t}\left\{F\left(f_{b}+\Delta p_{k}\right)\left(p_{k, d}-c\right)+\left(1-F\left(f_{b}+\Delta p_{k}\right)\right)\left(p_{k, m}-f_{s}\right)\right\}
\end{aligned}
$$

and

$$
\begin{aligned}
& \left\{1-F\left(f_{b}+\Delta p_{k}\right)-f\left(f_{b}+\Delta p_{k}\right)\left(\Delta p_{k}-f_{s}+c\right)\right\} \times\left\{M_{m}+M_{d}\right\} \\
= & 9 \frac{M_{m}}{t}\left\{F\left(f_{b}+\Delta p_{k}\right)\left(p_{k, d}-c\right)+\left(1-F\left(f_{b}+\Delta p_{k}\right)\right)\left(p_{k, m}-f_{s}\right)\right\} .
\end{aligned}
$$

Setting equal the equations which result after dividing the first equation by $\frac{M_{d}}{t}$ and the second equation by $\frac{M_{m}}{t}$ yields

$$
\begin{aligned}
& \left\{F\left(f_{b}+\Delta p_{k}\right)+f\left(f_{b}+\Delta p_{k}\right)\left(\Delta p_{k}-f_{s}+c\right)\right\} \times \frac{t\left(M_{m}+M_{d}\right)}{M_{d}} \\
= & \left\{1-F\left(f_{b}+\Delta p_{k}\right)-f\left(f_{b}+\Delta p_{k}\right)\left(\Delta p_{k}-f_{s}+c\right)\right\} \times \frac{t\left(M_{m}+M_{d}\right)}{M_{m}},
\end{aligned}
$$

which is equivalent to

$$
F\left(f_{b}+\Delta p_{k}\right)+f\left(f_{b}+\Delta p_{k}\right)\left\{\Delta p_{k}-f_{s}+c\right\}=\frac{M_{d}}{M_{d}+M_{m}} .
$$

Application of the implicit function theorem proves proposition 1

$$
\begin{gathered}
\frac{\partial \cdot}{\partial \Delta p}=2 f\left(f_{b}+\Delta p\right)+f^{\prime}\left(f_{b}+\Delta p\right)\left\{\Delta p+c-f_{s}\right\} \\
\frac{\partial \cdot}{\partial f_{s}}=-f\left(f_{b}+\Delta p\right) \\
\frac{\partial \cdot}{\partial f_{b}}=f\left(f_{b}+\Delta p\right)+f^{\prime}\left(f_{b}+\Delta p\right)\left\{\Delta p+c-f_{s}\right\} \\
\frac{\partial \Delta p}{\partial f_{s}}=-\frac{\frac{\partial \cdot}{\partial f_{s}}}{\frac{\partial \cdot}{\partial \Delta p}}=\frac{1}{2}-\frac{f^{\prime}\left(f_{b}+\Delta p\right)\left\{\Delta p+c-f_{s}\right\}}{2\left\{2 f\left(f_{b}+\Delta p\right)+f^{\prime}\left(f_{b}+\Delta p\right)\left\{\Delta p+c-f_{s}\right\}\right\}} \\
\frac{\partial \Delta p}{\partial f_{b}}=-\frac{\frac{\partial \cdot}{\partial f_{b}}}{\frac{\partial \cdot}{\partial \Delta p}}=-\frac{1}{2}-\frac{f^{\prime}\left(f_{b}+\Delta p\right)\left\{\Delta p+c-f_{s}\right\}}{2\left\{2 f\left(f_{b}+\Delta p\right)+f^{\prime}\left(f_{b}+\Delta p\right)\left\{\Delta p+c-f_{s}\right\}\right\}}
\end{gathered}
$$

As the indifferent consumer between channels is given by $\widetilde{v}=f_{b}+\Delta p$, it follows that

$$
\frac{\partial \widetilde{v}}{\partial f_{b}}=\frac{\partial \widetilde{v}}{\partial f_{s}} .
$$

Hence, if $f_{b}+f_{s}=$ const., a marginal shift between $f_{b}$ and $f_{s}$ does not change $\widetilde{v}$, and the split-up of consumers between marketplace and direct sales channel remains unchanged. 
Prices under uniformly distributed platform benefits (full participation, no NDR)

Bringing together equation (1) and assumption 1 , it follows that

$$
\Delta p_{k}=f_{s}-c+\frac{\frac{M_{d}}{M_{d}+M_{m}}-\frac{\left(f_{b}+\Delta p_{k}\right)-\underline{v}}{\overline{\bar{v}}-\underline{v}}}{\frac{1}{\bar{\nu}-\underline{v}}} \Leftrightarrow \Delta p_{k}=\frac{1}{2} \cdot\left(\frac{M_{d}}{M_{d}+M_{m}} \cdot(\bar{v}-\underline{v})+\underline{v}+f_{s}-f_{b}-c\right),
$$

which confirms equation (2).

Plugging $\Delta p_{k}$ into the first order condition w.r.t. $p_{k, d}$, i.e., equation [19), leads to

$$
\begin{aligned}
& \left\{f_{b}+\left(\frac{M_{d}}{M_{d}+M_{m}}(\bar{v}-\underline{v})+\underline{v}+f_{s}-f_{b}-c\right)-\underline{v}+c-f_{s}\right\} \times \frac{t\left(M_{m}+M_{d}\right)}{9 M_{d}} \\
= & \left(p_{k, m}-f_{s}\right)(\bar{v}-\underline{v}) \\
& -\left\{f_{b}+\frac{1}{2}\left(\frac{M_{d}}{M_{d}+M_{m}}(\bar{v}-\underline{v})+\underline{v}+f_{s}-f_{b}-c\right)-\underline{v}\right\} \\
& \times\left(\frac{1}{2}\left(\frac{M_{d}}{M_{d}+M_{m}}(\bar{v}-\underline{v})+\underline{v}+f_{s}-f_{b}-c\right)+c-f_{s}\right) .
\end{aligned}
$$

This is equivalent to

$$
\frac{1}{4}\left(\frac{M_{d}}{M_{d}+M_{m}}(\bar{v}-\underline{v})-x\right) \cdot\left(\frac{M_{d}}{M_{d}+M_{m}}(\bar{v}-\underline{v})+x\right)=\left(p_{k, m}-f_{s}-\frac{t}{9}\right)(\bar{v}-\underline{v}),
$$

with $x=\underline{v}-f_{s}-f_{b}+c$. Solving for $p_{k, m}$, taking into account that $F_{u}\left(\widetilde{v}\left(f_{b}+f_{s}\right)\right)=\frac{\widetilde{v}\left(f_{b}+f_{s}\right)-\underline{\underline{v}}}{\bar{v}-\underline{\underline{v}}}$, with $\widetilde{v}\left(f_{b}+\right.$ $f_{s}$ ) as defined in equation (3), yields (4); (5) follows from $p_{k, d}=p_{k, m}-\Delta p_{k}$.

\section{Proof of proposition 2}

In the symmetric equilibrium derived above, each seller's profit equals

$$
\pi^{*}=\frac{1}{3} \cdot\left(M_{d}+M_{m}\right) \cdot\left\{F_{u}\left(\widetilde{v}\left(f_{b}+f_{s}\right)\right) \cdot\left(p_{k, d}-c\right)+\left(1-F_{u}\left(\widetilde{v}\left(f_{b}+f_{s}\right)\right)\right) \cdot\left(p_{k, m}-f_{s}\right)\right\} .
$$

Inserting equilibrium prices (4) and (5) leads to

$$
\begin{aligned}
3 \cdot \frac{\pi^{*}}{M_{d}+M_{m}} & =F_{u}\left(\widetilde{v}\left(f_{b}+f_{s}\right) \cdot\left(\frac{t}{9}-\left\{1-F_{u}\left(\widetilde{v}\left(f_{b}+f_{s}\right)\right)\right\} \cdot\left(\frac{M_{d}}{M_{d}+M_{m}}-\frac{f_{b}+f_{s}-c-\underline{v}}{\bar{v}-\underline{v}}\right) \cdot\left(\frac{\bar{v}-\underline{v}}{2}\right)\right)\right. \\
& +\left(1-F_{u}\left(\widetilde{v}\left(f_{b}+f_{s}\right)\right) \cdot\left(\frac{t}{9}+F_{u}\left(\widetilde{v}\left(f_{b}+f_{s}\right)\right) \cdot\left(\frac{M_{d}}{M_{d}+M_{m}}-\frac{f_{b}+f_{s}-c-\underline{v}}{\bar{v}-\underline{v}}\right) \cdot\left(\frac{\bar{v}-\underline{v}}{2}\right)\right) .\right.
\end{aligned}
$$

This simplifies to $3 \cdot \frac{\pi^{*}}{M_{d}+M_{m}}=\frac{t}{9}$. Hence, equilibrium profit equals $\frac{t}{27} \cdot\left(M_{d}+M_{m}\right)$.

\section{Proof of proposition 3}

Firstly, I show that specialization on the direct sales channel is not profitable without a NDR, given condition (6) in assumption 2

If seller 1 specializes on the direct sales channel while sellers 2 and 3 are active in both channels, without a NDR, profits read

$$
\pi_{1}=M_{d}\left(\frac{1}{3}+3 \frac{p_{2, d}+p_{3, d}-2 p_{1}}{2 t}\right)\left(p_{1}-c\right)
$$

and

$$
\begin{aligned}
\pi_{2}=\{ & \left.M_{d}\left(\frac{1}{3}+3 \frac{p_{1}+p_{3, d}-2 p_{2, d}}{2 t}\right)+M_{m}\left(\frac{1}{2}+2 \frac{p_{3, m}-p_{2, m}}{t}\right)\right\} \\
& \times\left\{F\left(f_{b}+\Delta p\right)\left(p_{2, d}-c\right)+\left(1-F\left(f_{b}+\Delta p\right)\right)\left(p_{2, m}-f_{s}\right)\right\} .
\end{aligned}
$$


As before, $\Delta p_{k} \equiv p_{k, m}-p_{k, d}$, and $\gamma \equiv \frac{M_{m}}{M_{d}}$. The best response of seller 1 can be calculated as

$$
p_{1}\left(p_{2, d}, p_{3, d}\right)=\frac{t}{18}+\frac{c}{2}+\frac{p_{2, d}+p_{3, d}}{4} .
$$

The partial derivatives of $\pi_{2}$ are

$$
\begin{aligned}
\frac{\partial \pi_{2}}{\partial p_{2, d}}= & -\frac{3 M_{d}}{t}\left\{\left(p_{2, m}-f_{s}\right)-F\left(f_{b}+\Delta p\right)\left(\Delta p-f_{s}+c\right)\right\} \\
& +\left\{M_{d}\left(\frac{1}{3}+3 \frac{p_{1}+p_{3, d}-2 p_{2, d}}{2 t}\right)+M_{m}\left(\frac{1}{2}+2 \frac{p_{3, m}-p_{2, m}}{t}\right)\right\} \\
& \times\left(F\left(f_{b}+\Delta p\right)+f\left(f_{b}+\Delta p\right)\left(\Delta p-f_{s}+c\right)\right)
\end{aligned}
$$

and

$$
\begin{aligned}
\frac{\partial \pi_{2}}{\partial p_{2, m}}= & -\frac{2 M_{m}}{t}\left\{\left(p_{2, m}-f_{s}\right)-F\left(f_{b}+\Delta p\right)\left(\Delta p-f_{s}+c\right)\right\} \\
+ & \left\{M_{d}\left(\frac{1}{3}+3 \frac{p_{1}+p_{3, d}-2 p_{2, d}}{2 t}\right)+M_{m}\left(\frac{1}{2}+2 \frac{p_{3, m}-p_{2, m}}{t}\right)\right\} \\
& \times\left(1-F\left(f_{b}+\Delta p\right)-f\left(f_{b}+\Delta p\right)\left(\Delta p-f_{s}+c\right)\right) .
\end{aligned}
$$

Setting equal the last two derivatives (first order conditions) yields

$$
\frac{1}{3 M_{d}}\left(F\left(f_{b}+\Delta p\right)+f\left(f_{b}+\Delta p\right)\left(\Delta p-f_{s}+c\right)\right)=\frac{1}{2 M_{m}}\left(1-F\left(f_{b}+\Delta p\right)-f\left(f_{b}+\Delta p\right)\left(\Delta p-f_{s}+c\right)\right),
$$

which is equivalent to

$$
\frac{3}{3+2 \gamma}=F\left(f_{b}+\Delta p\right)+f\left(f_{b}+\Delta p\right)\left(\Delta p-f_{s}+c\right) .
$$

With uniformly distributed platform benefits, this leads to

$$
\Delta p=\frac{1}{2}\left(\frac{3}{3+2 \gamma}(\bar{v}-\underline{v})+\underline{v}+f_{s}-f_{b}-c\right) .
$$

From $\frac{\partial \pi_{2}}{\partial p_{2, d}}=0$ and symmetry $p_{2, d}=p_{3, d}$, by inserting seller 1's best response, it follows

$$
\begin{aligned}
& \frac{3 M_{d}}{t}\left\{\left(\Delta p+p_{2, d}-f_{s}\right)-F_{u}\left(f_{b}+\Delta p\right)\left(\Delta p-f_{s}+c\right)\right\} \\
= & \left\{M_{d}\left(\frac{1}{3}+3 \frac{\left(\frac{t}{18}+\frac{c}{2}+\frac{p_{2, d}}{2}\right)-p_{2, d}}{2 t}\right)+\frac{M_{m}}{2}\right\} \cdot\left(F_{u}\left(f_{b}+\Delta p\right)+f_{u}\left(f_{b}+\Delta p\right)\left(\Delta p-f_{s}+c\right)\right) .
\end{aligned}
$$

This is equivalent to

$$
\begin{aligned}
& \frac{3 M_{d}}{t}\left\{\left(\Delta p+p_{2, d}-f_{s}\right)-F_{u}\left(f_{b}+\Delta p\right)\left(\Delta p-f_{s}+c\right)\right\} \\
= & \left\{M_{d}\left(\frac{5}{12}+\frac{3}{4}\left(\frac{c}{t}-\frac{p_{2, d}}{t}\right)\right)+\frac{M_{m}}{2}\right\} \cdot\left(F_{u}\left(f_{b}+\Delta p\right)+f_{u}\left(f_{b}+\Delta p\right)\left(\Delta p-f_{s}+c\right)\right),
\end{aligned}
$$

or

$$
\begin{aligned}
& p_{2, d} \cdot\left(1+\frac{1}{4} \cdot\left(F_{u}\left(f_{b}+\Delta p\right)+f_{u}\left(f_{b}+\Delta p\right)\left(\Delta p-f_{s}+c\right)\right)\right) \\
= & \left\{\frac{5}{36} t+\frac{c}{4}+\frac{\gamma}{6} t\right\} \cdot\left(F_{u}\left(f_{b}+\Delta p\right)+f_{u}\left(f_{b}+\Delta p\right)\left(\Delta p-f_{s}+c\right)\right)+\left(1-F_{u}\left(f_{b}+\Delta p\right)\right) \cdot\left(f_{s}-c-\Delta p\right)+c .
\end{aligned}
$$


This can be simplified as follows:

$$
\begin{aligned}
p_{2, d}= & \frac{c+\left(F_{u}\left(f_{b}+\Delta p\right)-f_{u}\left(f_{b}+\Delta p\right)\left(f_{s}-c-\Delta p\right)\right) \cdot\left\{\left(\frac{5}{6}+\gamma\right) \cdot \frac{t}{6}+\frac{c}{4}\right\}+\left(1-F_{u}\left(f_{b}+\Delta p\right)\right) \cdot\left(f_{s}-c-\Delta p\right)}{1+\frac{1}{4} \cdot\left(F_{u}\left(f_{b}+\Delta p\right)-f_{u}\left(f_{b}+\Delta p\right)\left(f_{s}-c-\Delta p\right)\right)} \\
= & \frac{c+\left(\frac{\left(f_{b}+\Delta p\right)-\underline{v}}{(\bar{v}-\underline{v})}-\frac{\left(f_{s}-c-\Delta p\right)}{(\bar{v}-\underline{v})}\right) \cdot\left\{\left(\frac{5}{6}+\gamma\right) \cdot \frac{t}{6}+\frac{c}{4}\right\}+\left(1-\frac{\left(f_{b}+\Delta p\right)-\underline{v}}{(\bar{v}-\underline{v})}\right) \cdot\left(f_{s}-c-\Delta p\right)}{1+\frac{1}{4} \cdot\left(\frac{\left(f_{b}+\Delta p\right)-\underline{v}}{(\bar{v}-\underline{v})}-\frac{\left(f_{s}-c-\Delta p\right)}{(\bar{v}-\underline{v})}\right)} \\
= & \frac{4 c \cdot(\bar{v}-\underline{v})+\left(2 \Delta p+f_{b}+c-f_{s}-\underline{v}\right) \cdot\left\{\left(\frac{5}{6}+\gamma\right) \cdot \frac{2}{3} \cdot t+c\right\}+4 \cdot\left((\bar{v}-\underline{v})-\left(f_{b}+\Delta p-\underline{v}\right)\right) \cdot\left(f_{s}-c-\Delta p\right)}{4(\bar{v}-\underline{v})+2 \Delta p+f_{b}+c-f_{s}-\underline{v}} \\
= & c+\frac{\left(2 \Delta p+f_{b}+c-f_{s}-\underline{v}\right) \cdot\left(\frac{5}{6}+\gamma\right) \cdot \frac{2}{3} \cdot t+4 \cdot\left((\bar{v}-\underline{v})-\left(f_{b}+\Delta p-\underline{v}\right)\right) \cdot\left(f_{s}-c-\Delta p\right)}{4(\bar{v}-\underline{v})+2 \Delta p+f_{b}+c-f_{s}-\underline{v}} \\
= & c+\frac{(5+6 \gamma)}{(15+8 \gamma)} \cdot \frac{t}{3} \\
& -\frac{(6+4 \gamma)}{(15+8 \gamma)} \cdot\left(1-\frac{1}{2}\left(\frac{\frac{3}{3+2 \gamma}(\bar{v}-\underline{v})-\underline{v}+f_{b}+f_{s}-c}{(\bar{v}-\underline{v})}\right)\right) \cdot\left(\frac{3}{3+2 \gamma}(\bar{v}-\underline{v})+\underline{v}-f_{s}-f_{b}+c\right) .
\end{aligned}
$$

Inserting this price (which equals $p_{3, d}$ in equilibrium) into the best response function, the price of seller 1 turns out to be

$$
\begin{aligned}
p_{1}=c & +\frac{t}{18}+\frac{(5+6 \gamma)}{(15+8 \gamma)} \cdot \frac{t}{6} \\
& -\frac{1}{2} \cdot \frac{(6+4 \gamma)}{(15+8 \gamma)} \cdot\left(1-\frac{1}{2}\left(\frac{\frac{3}{3+2 \gamma}(\bar{v}-\underline{v})-\underline{v}+f_{b}+f_{s}-c}{(\bar{v}-\underline{v})}\right)\right) \cdot\left(\frac{3}{3+2 \gamma}(\bar{v}-\underline{v})+\underline{v}-f_{s}-f_{b}+c\right) .
\end{aligned}
$$

Observing that

$$
\begin{aligned}
p_{2, d}-p_{1}= & \underbrace{\frac{(5+6 \gamma)-\left(5+\frac{8}{3} \gamma\right)}{(15+8 \gamma)} \cdot \frac{t}{6}}_{=\frac{10 \gamma}{15+8 \gamma} \cdot \frac{t}{18}} \\
& -\frac{1}{2} \cdot \frac{(6+4 \gamma)}{(15+8 \gamma)} \cdot\left(1-\frac{1}{2}\left(\frac{\frac{3}{3+2 \gamma}(\bar{v}-\underline{v})-\underline{v}+f_{b}+f_{s}-c}{(\bar{v}-\underline{v})}\right)\right) \cdot\left(\frac{3}{3+2 \gamma}(\bar{v}-\underline{v})+\underline{v}-f_{s}-f_{b}+c\right),
\end{aligned}
$$

the profit of seller 1 (specializing on direct sales) is given by

$$
\begin{aligned}
\pi_{1}^{d e v}= & M_{d}\left(\frac{1}{3}+\frac{3}{2 t} \cdot\left\{\frac{10 \gamma}{15+8 \gamma} \cdot \frac{t}{9}+\frac{(6+4 \gamma)}{(15+8 \gamma)} \cdot\left(1-\frac{1}{2}\left(\frac{\frac{3}{3+2 \gamma}(\bar{v}-\underline{v})-\underline{v}+f_{b}+f_{s}-c}{(\bar{v}-\underline{v})}\right)\right) \cdot\left(f_{b}+f_{s}-c-\underline{v}-\frac{3}{3+2 \gamma}(\bar{v}-\underline{v})\right)\right\}\right) \\
& \times\left(\frac{t}{18}+\frac{1}{2} \cdot\left\{\frac{(5+6 \gamma)}{(15+8 \gamma)} \cdot \frac{t}{3}+\frac{(6+4 \gamma)}{(15+8 \gamma)} \cdot\left(1-\frac{1}{2}\left(\frac{\frac{3}{3+2 \gamma}(\bar{v}-\underline{v})-\underline{v}+f_{b}+f_{s}-c}{(\bar{v}-\underline{v})}\right)\right) \cdot\left(f_{b}+f_{s}-c-\underline{v}-\frac{3}{3+2 \gamma}(\bar{v}-\underline{v})\right)\right\}\right) \\
= & \frac{3 M_{d}}{t}\left(\frac{t}{9}+\frac{1}{2} \cdot\left\{\frac{10 \gamma}{15+8 \gamma} \cdot \frac{t}{9}+\frac{(6+4 \gamma)}{(15+8 \gamma)} \cdot\left(1-\frac{1}{2}\left(\frac{\frac{3}{3+2 \gamma}(\bar{v}-\underline{v})-\underline{v}+f_{b}+f_{s}-c}{(\bar{v}-\underline{v})}\right)\right) \cdot\left(f_{b}+f_{s}-c-\underline{v}-\frac{3}{3+2 \gamma}(\bar{v}-\underline{v})\right)\right\}\right)
\end{aligned}
$$

Specialization on direct sales is not profitable if $\pi_{1}^{d e v} \leq(1+\gamma) \cdot M_{d} \cdot \frac{t}{27}$, which is equivalent to

$$
\begin{aligned}
& \left|15+13 \gamma+9 \cdot(3+2 \gamma) \cdot\left(1-\frac{1}{2}\left(\frac{\frac{3}{3+2 \gamma}(\bar{v}-\underline{v})+f_{b}+f_{s}-c-\underline{v}}{(\bar{v}-\underline{v})}\right)\right) \cdot\left(\frac{f_{b}+f_{s}-c-\underline{v}-\frac{3}{3+2 \gamma}(\bar{v}-\underline{v})}{t}\right)\right| \\
& \leq(15+8 \gamma) \cdot \sqrt{1+\gamma} .
\end{aligned}
$$

As $p_{1}-c$ has to be positive for $\pi_{1}^{d e v}$ being positive (this is an implicit assumption made above), specialization is not profitable if

$$
\begin{aligned}
& 9 \cdot(3+2 \gamma) \cdot\left(1-\frac{1}{2}\left(\frac{\frac{3}{3+2 \gamma}(\bar{v}-\underline{v})+f_{b}+f_{s}-c-\underline{v}}{(\bar{v}-\underline{v})}\right)\right) \cdot\left(\frac{f_{b}+f_{s}-c-\underline{v}-\frac{3}{3+2 \gamma}(\bar{v}-\underline{v})}{t}\right) \\
& \leq(15+8 \gamma) \cdot \sqrt{1+\gamma}-(15+13 \gamma) .
\end{aligned}
$$


This can also be written as

$$
\begin{aligned}
& 9 \cdot\left(\frac{\bar{v}-\underline{v}}{t}\right) \cdot(3+2 \gamma) \cdot\left[\frac{f_{b}+f_{s}-(c+\underline{v})}{\bar{v}-\underline{v}}-\frac{3}{3+2 \gamma}-\frac{1}{2}\left\{\left(\frac{f_{b}+f_{s}-(c+\underline{v})}{\bar{v}-\underline{v}}\right)^{2}-\frac{9}{(3+2 \gamma)^{2}}\right\}\right] \\
& \leq(15+8 \gamma) \cdot \sqrt{1+\gamma}-(15+13 \gamma) .
\end{aligned}
$$

The left-hand side of this inequality takes its maximum at $f_{b}+f_{s}=(c+\underline{v})+(\bar{v}-\underline{v})$ (this fee level maximizes specialization incentives). Hence, the condition is fulfilled whenever

$$
9 \cdot\left(\frac{\bar{v}-\underline{v}}{t}\right) \cdot\left[2 \gamma-\frac{3+2 \gamma}{2}+\frac{9}{2} \cdot \frac{1}{3+2 \gamma}\right] \leq(15+8 \gamma) \cdot \sqrt{1+\gamma}-(15+13 \gamma)
$$

which is equivalent to condition [6].

Along the same lines, it can be shown that specialization on platform sales is not profitable to a seller, given condition (7) in assumption 2, If seller 1 specializes on platform sales, profits are as follows:

$$
\begin{gathered}
\pi_{1}=M_{m}\left(\frac{1}{3}+3 \frac{p_{2, m}+p_{3, m}-2 p_{1}}{2 t}\right)\left(p_{1}-f_{s}\right), \\
\pi_{2}=\left\{M_{m}\left(\frac{1}{3}+3 \frac{p_{1}+p_{3, m}-2 p_{2, m}}{2 t}\right)+M_{d}\left(\frac{1}{2}+2 \frac{p_{3, d}-p_{2, d}}{t}\right)\right\} \\
\times\left\{F\left(f_{b}+\Delta p\right)\left(p_{2, d}-c\right)+\left(1-F\left(f_{b}+\Delta p\right)\right)\left(p_{2, m}-f_{s}\right)\right\} .
\end{gathered}
$$

With uniformly distributed additional platform benefits, the relevant prices under specialization can be calculated as

$p_{2, m}=f_{s}+\frac{5 \gamma+6}{15 \gamma+8} \cdot \frac{t}{3}+\frac{1}{(\bar{v}-\underline{v})} \cdot \frac{2+3 \gamma}{8+15 \gamma} \cdot\left(\frac{2}{2+3 \gamma} \cdot(\bar{v}-\underline{v})+f_{b}+f_{s}-c-\underline{v}\right) \cdot\left(\frac{2}{2+3 \gamma} \cdot(\bar{v}-\underline{v})-f_{s}-f_{b}+c+\underline{v}\right)$,

and

$p_{1}=f_{s}+\frac{t}{18}+\frac{1}{2} \cdot\left\{\frac{5 \gamma+6}{15 \gamma+8} \cdot \frac{t}{3}+\frac{1}{(\bar{v}-\underline{v})} \cdot \frac{2+3 \gamma}{8+15 \gamma} \cdot\left(\frac{2}{2+3 \gamma} \cdot(\bar{v}-\underline{v})+f_{b}+f_{s}-c-\underline{v}\right) \cdot\left(\frac{2}{2+3 \gamma} \cdot(\bar{v}-\underline{v})-f_{s}-f_{b}+c+\underline{v}\right)\right\}$.

Specialization is not profitable to seller 1 if

$$
9 \cdot \frac{(\bar{v}-\underline{v})}{t} \cdot\left(\frac{2}{(2+3 \gamma)}-\frac{(2+3 \gamma)}{2} \cdot\left(\frac{f_{b}+f_{s}-(c+\underline{v})}{(\bar{v}-\underline{v})}\right)^{2}\right) \leq(15 \gamma+8) \cdot \sqrt{\frac{1+\gamma}{\gamma}}-(15 \gamma+13) .
$$

The left-hand side takes its maximum for $f_{b}+f_{s}=c+\underline{v}$. Hence, specialization is never profitable under condition 7 .

\section{Derivation of prices under NDR when one seller specializes on direct sales}

Given the profit of seller 1,

$$
\pi_{1}(\mathbf{p})=M_{d} \cdot\left(\frac{1}{3}+3 \cdot \frac{p_{2}+p_{3}-2 \cdot p_{1}}{2 t}\right) \cdot\left(p_{1}-c\right),
$$

her best response on prices $p_{2}$ and $p_{3}$ can be calculated as

$$
p_{1}^{\operatorname{dev}}\left(p_{2}, p_{3}\right)=\frac{t}{18}+\frac{p_{2}+p_{3}}{4}+\frac{c}{2} .
$$

After deriving the profit of seller 2,

$$
\begin{aligned}
\pi_{2}(\mathbf{p})= & M_{d} \cdot\left(\frac{1}{3}+3 \cdot \frac{p_{1}+p_{3}-2 \cdot p_{2}}{2 t}\right) \cdot\left\{p_{2}-F\left(f_{b}\right) \cdot c-\left(1-F\left(f_{b}\right)\right) \cdot f_{s}\right\} \\
& +M_{m} \cdot\left(\frac{1}{2}+2 \cdot \frac{p_{3}-p_{2}}{t}\right) \cdot\left\{p_{2}-F\left(f_{b}\right) \cdot c-\left(1-F\left(f_{b}\right)\right) \cdot f_{s}\right\},
\end{aligned}
$$


it follows that the respective first order condition in an equilibrium that features symmetry between sellers 2 and 3, i.e., $p_{2}=p_{3}$, is equivalent to

$$
p_{2}^{d e v}=\frac{6 \cdot\left(3 \cdot M_{d}+2 \cdot M_{m}\right) \cdot\left\{F\left(f_{b}\right) \cdot c+\left(1-F\left(f_{b}\right)\right) \cdot f_{s}\right\}+\left(2 \cdot M_{d}+3 \cdot M_{m}\right) \cdot t+9 \cdot M_{d} \cdot p_{1}^{d e v}}{27 \cdot M_{d}+12 \cdot M_{m}}
$$

Inserting the best response of seller 1 leads to

$$
p_{1}^{d e v}=\left(1+\frac{5 \gamma}{15+8 \gamma}\right) \cdot \frac{t}{9}+c+\left(1-\frac{9+4 \gamma}{15+8 \gamma}\right) \cdot\left(1-F\left(f_{b}\right)\right) \cdot\left(f_{s}-c\right)
$$

and

$$
p_{2}^{d e v}=p_{3}^{d e v}=\left(1+\frac{10 \gamma}{15+8 \gamma}\right) \cdot \frac{t}{9}+c+\left(1-\frac{3}{15+8 \gamma}\right) \cdot\left(1-F\left(f_{b}\right)\right) \cdot\left(f_{s}-c\right),
$$

where $\gamma=\frac{M_{m}}{M_{d}}$.

These prices indeed constitute an equilibrium if a unilateral (discrete) deviation, in particular undercutting the other sellers to serve all consumers, is not profitable. With quadratic transportation costs, a deviation is not profitable if the calculated prices imply positive market shares for all sellers, i.e.,

As

$$
p_{1}^{d e v}+\left(\frac{1}{2}\right)^{2} \cdot t>p_{2}^{d e v}+\left(\frac{1}{6}\right)^{2} \cdot t \Leftrightarrow p_{2}^{d e v}-p_{1}^{d e v}<\left(\frac{1}{4}-\frac{1}{36}\right) \cdot t=\frac{2}{9} \cdot t .
$$

$$
p_{2}^{d e v}-p_{1}^{d e v}=\frac{5 \gamma}{15+8 \gamma} \cdot \frac{t}{9}+\left(\frac{6+4 \gamma}{15+8 \gamma}\right) \cdot\left(1-F\left(f_{b}\right)\right) \cdot\left(f_{s}-c\right),
$$

this condition is equivalent to

$$
\left(1-F\left(f_{b}\right)\right) \cdot\left(f_{s}-c\right)<\left(2-\frac{5 \gamma}{15+8 \gamma}\right) \cdot\left(\frac{15+8 \gamma}{6+4 \gamma}\right) \cdot \frac{t}{9}=\left(\frac{30+11 \gamma}{2 \cdot(3+2 \gamma)}\right) \cdot \frac{t}{9}
$$

This condition is always fulfilled if both specialization on direct sales is not profitable (condition (11)) and $\gamma<8$, cf. the subsequent analysis.

\section{Proof of proposition 5}

Inserting the price difference given in equation (21) and $p_{1}^{\text {dev }}$ defined in 9] into the profit function of seller 1 , her profit can be rewritten as

$$
3 \cdot M_{d} \cdot t \cdot\left(\frac{15+13 \gamma}{15+8 \gamma} \cdot \frac{1}{9}+\left(\frac{6+4 \gamma}{15+8 \gamma}\right) \cdot\left(1-F\left(f_{b}\right)\right) \cdot \frac{f_{s}-c}{t}\right)^{2}
$$

If all sellers are active in both channels, each seller earns a profit of $(1+\gamma) \cdot M_{d} \cdot \frac{t}{27}$. Consequently, a unilateral specialization on direct sales is not profitable if

$$
3 \cdot\left(\frac{15+13 \gamma}{15+8 \gamma} \cdot \frac{1}{9}+\left(\frac{6+4 \gamma}{15+8 \gamma}\right) \cdot\left(1-F\left(f_{b}\right)\right) \cdot \frac{f_{s}-c}{t}\right)^{2} \leq \frac{1+\gamma}{27}
$$

This condition holds if condition (11) is fulfilled.

As $p_{1}^{\text {dev }} \geq 0$, the second alternative,

$$
\frac{15+13 \gamma}{15+8 \gamma} \cdot \frac{1}{9}+\left(\frac{6+4 \gamma}{15+8 \gamma}\right) \cdot\left(1-F\left(f_{b}\right)\right) \cdot \frac{f_{s}-c}{t} \leq-\frac{\sqrt{1+\gamma}}{9}
$$

is irrelevant.

Taking a closer look on the upper bound (right-hand side) of condition [11, it can be shown that it does not exceed the upper bound given just above in condition 22 if $\gamma \leq 8$. Hence, condition (11] ensures existence of the asymmetric specialization equilibrium (as a non-profitable outside option). 


\section{Condition: Non-profitability of unilateral specialization on platform sales under a NDR}

Along the lines of the derivation of the prices under NDR when one seller specializes on direct sales, the best response of seller 1 can be calculated as

$$
p_{1}^{d e v}\left(p_{2}, p_{3}\right)=\frac{t}{18}+\frac{p_{2}+p_{3}}{4}+\frac{f_{s}}{2} .
$$

In an equilibrium that features symmetry between seller 2 and 3 (i.e., $p_{2}=p_{3}$ ), the first order condition which follows from the maximization of the profit of a non-specializing seller is equivalent to

$$
F\left(f_{b}\right) \cdot c+\left(1-F\left(f_{b}\right)\right) \cdot f_{s}+\frac{t}{2 M_{d}+3 M_{m}} \cdot\left\{\frac{M_{d}}{2}+\frac{M_{m}}{3}+\frac{3 M_{m}}{2 t} \cdot p_{1}\right\}=\frac{2 M_{d}+\frac{9}{2} M_{m}}{2 M_{d}+3 M_{m}} \cdot p_{2} .
$$

Inserting the best response of seller 1 leads to the prices

$$
p_{1}^{d e v}=\left(1+\frac{5}{15 \gamma+8}\right) \cdot \frac{t}{9}+f_{s}+\left(1-\frac{9 \gamma+4}{15 \gamma+8}\right) \cdot F\left(f_{b}\right) \cdot\left(c-f_{s}\right),
$$

and

$$
p_{2}^{d e v}=p_{3}^{d e v}=\left(1+\frac{10}{15 \gamma+8}\right) \cdot \frac{t}{9}+f_{s}+\left(1-\frac{3 \gamma}{15 \gamma+8}\right) \cdot F\left(f_{b}\right) \cdot\left(c-f_{s}\right) .
$$

The profit of seller 1 under specialization equals

$$
\pi_{1}^{d e v}=M_{m} \cdot 3 \cdot t \cdot\left(\frac{1}{9} \cdot\left(1+\frac{5}{15 \gamma+8}\right)+F\left(f_{b}\right) \cdot \frac{6 \gamma+4}{15 \gamma+8} \cdot \frac{c-f_{s}}{t}\right)^{2} .
$$

Consequently, specialization on platform sales is not profitable under a NDR if

$$
-F\left(f_{b}\right) \cdot\left(f_{s}-c\right) \leq \frac{t}{9} \cdot\left(\frac{(15 \gamma+8) \cdot \sqrt{1+\frac{1}{\gamma}}-(15 \gamma+13)}{2 \cdot(3 \gamma+2)}\right),
$$

where the right-hand side is strictly positive for $\gamma>0$.

The calculated prices under specialization indeed constitute an equilibrium (in the pricing game) if

$$
-F\left(f_{b}\right) \cdot\left(f_{s}-c\right) \leq \frac{t}{9} \cdot \frac{11+30 \gamma}{4+6 \gamma} .
$$

This condition is implied by the non-profitability condition if $\gamma \geq \frac{1}{8}$.

\section{Quantitative effect of a change in locations of non-specialized sellers}

All profits in the main body are calculated under the assumption that sellers are always located such that the distance to their next competitor in clockwise order is the same as the distance to their next competitor in counter-clockwise order. In particular, if seller 1 specializes on channel $j$, the positions of the non-specialized sellers 2 and 3 fulfill $\left|x_{3}-x_{2}\right|=\frac{1}{2}$ in channel $i \neq j$, while the distance between any two sellers in channel $j$ equals $\frac{1}{3}$.

If the non-specialized sellers 2 and 3 are located as in the case with three sellers (i.e., at $x_{2}=\frac{1}{3}$ and $\left.x_{3}=\frac{2}{3}\right)$, demand for product $k \neq l$ in channel $i$ equals

$$
q_{k, i}\left(p_{2, i}, p_{3, i}\right)=\frac{1}{2}+\frac{9}{4} \cdot \frac{p_{l, i}-p_{k, i}}{t} .
$$

Therefore, the "relaxed competition" effect is weaker than with perfectly symmetric positions (where the factor that is multiplied by the (relative) price difference equals $2<\frac{9}{4}$ ), and the price increase due to specialization is less pronounced. Therefore, the condition for specialization on direct sales not being profitable is less demanding than before, making the no-discrimination rule (slightly) 
more attractive to the intermediary. More specifically, if the locations of the non-specialized sellers are the same in both channels, regardless of the third seller being present, the upper bound on $\left(1-F\left(f_{b}\right)\right) \cdot\left(f_{s}-c\right)$ in condition 11 becomes

$$
\frac{t}{9} \cdot\left(\frac{(10+6 \gamma) \cdot \sqrt{1+\gamma}-(10+9 \gamma)}{4+3 \gamma}\right)
$$

However, all trade-offs remain qualitatively unchanged and, therefore, the results are robust against changes in the locations of the non-specialized sellers in the "outside option" scenario.

\section{Proof of lemma2}

Without a NDR, the intermediary's profit equals $(1+\gamma) \cdot M_{d} \cdot\left\{1-F\left(\widetilde{v}\left(f_{b}+f_{s}\right)\right)\right\} \cdot\left(f_{b}+f_{s}-k\right)$.

Without loss of generality, I set $f_{b}=0$ to calculate the optimal fee (without a NDR the fee structure features neutrality). Then, the first order condition w.r.t. $f_{s}$ is given by

$$
1-F\left(\Delta p_{k}\right)=f\left(\Delta p_{k}\right) \cdot \frac{\partial \Delta p_{k}}{\partial f_{s}} \cdot\left(f_{s}-k\right) \text {. }
$$

Consequently, without a no-discrimination rule, given assumption (1) and using definition (8), the platform operator's profit is maximized by setting

$$
f_{b}+f_{s}=c+\underline{v}+\frac{(k-c)-\underline{v}}{2}+(\bar{v}-\underline{v}) \cdot\left(1-\frac{1}{2(1+\gamma)}\right) .
$$

Given this fee level, the indifferent consumer between channels, defined in (3), turns out to be

$$
\widetilde{v}\left(f_{b}+f_{s}\right)=\underline{v}+\frac{1}{2} \cdot(\bar{v}-\underline{v}) \cdot\left(\frac{1}{1+\gamma}+\frac{(k-c)-\underline{v}}{2 \cdot(\bar{v}-\underline{v})}+1-\frac{1}{2(1+\gamma)}\right) .
$$

Hence, the maximal profit equals

$$
\begin{aligned}
\Pi_{0}^{*} & =(1+\gamma) \cdot M_{d} \cdot\left\{1-F_{u}\left(\widetilde{v}\left(f_{b}+f_{s}\right)\right)\right\} \cdot\left(f_{b}+f_{s}-k\right) \\
& =(1+\gamma) \cdot M_{d} \cdot\left\{1-\frac{(k-c)-\underline{v}}{4 \cdot(\bar{v}-\underline{v})}-\frac{1}{2}-\frac{1}{4(1+\gamma)}\right\} \cdot\left(c+\underline{v}+\frac{(k-c)-\underline{v}}{2}+(\bar{v}-\underline{v}) \cdot\left(1-\frac{1}{2(1+\gamma)}\right)-k\right) \\
& =(1+\gamma) \cdot M_{d} \cdot \frac{1}{2} \cdot\left\{1-\frac{(k-c)-\underline{v}}{2 \cdot(\bar{v}-\underline{v})}-\frac{1}{2(1+\gamma)}\right\} \cdot(\bar{v}-\underline{v}) \cdot\left(-\frac{(k-c)-\underline{v}}{2 \cdot(\bar{v}-\underline{v})}+1-\frac{1}{2(1+\gamma)}\right) \\
& =(1+\gamma) \cdot M_{d} \cdot\left(\frac{\bar{v}-\underline{v}}{2}\right) \cdot\left\{1-\frac{1}{2} \cdot\left(F_{u}(k-c)+\frac{1}{1+\gamma}\right)\right\}^{2} .
\end{aligned}
$$

\section{Proof of lemma 3}

In order to maximize the profit given in [14], the intermediary sets the maximal seller fee that is compatible with participation constraint [1], i.e.,

$$
f_{s}^{*}=c+\frac{t}{9} \cdot\left(\frac{(15+8 \gamma) \cdot \sqrt{1+\gamma}-(15+13 \gamma)}{2 \cdot(3+2 \gamma) \cdot\left(1-F\left(f_{b}\right)\right)}\right)
$$

Inserting this fee into the intermediary's profit (14) yields

$$
\begin{aligned}
\Pi_{1}\left(f_{b}\right) & =\left(M_{d}+M_{m}\right) \cdot\left(1-F\left(f_{b}\right)\right) \cdot\left(c+\frac{t}{9} \cdot\left(\frac{(15+8 \gamma) \cdot \sqrt{1+\gamma}-(15+13 \gamma)}{2 \cdot(3+2 \gamma) \cdot\left(1-F\left(f_{b}\right)\right)}\right)+f_{b}-k\right) \\
& =\left(M_{d}+M_{m}\right) \cdot\left\{\frac{t}{9} \cdot\left(\frac{(15+8 \gamma) \cdot \sqrt{1+\gamma}-(15+13 \gamma)}{2 \cdot(3+2 \gamma)}\right)+\left(1-F\left(f_{b}\right)\right) \cdot\left(f_{b}-(k-c)\right)\right\} .
\end{aligned}
$$

Under assumption [1, this expression takes its maximum at $f_{b}^{*}=\frac{k-c}{2}+\frac{\bar{v}}{2}$. The corresponding profit level equals

$$
\Pi_{1}^{*}=\left(M_{d}+M_{m}\right) \cdot\left\{\frac{t}{9} \cdot\left(\frac{(15+8 \gamma) \cdot \sqrt{1+\gamma}-(15+13 \gamma)}{2 \cdot(3+2 \gamma)}\right)+\left(\frac{\bar{v}-\underline{v}}{4}\right) \cdot\left(1-F_{u}(k-c)\right)^{2}\right\} .
$$




\section{Proof of proposition 7}

Imposing a no-discrimination rule always results in an underuse of the platform channel, cf. corollary 5 However, imposing a no-discrimination rule improves the allocation of consumers on channels if

$$
1-F_{u}\left(\widetilde{v}_{1}\right)>1-F_{u}\left(\widetilde{v}_{0}\right) \Leftrightarrow \widetilde{v}_{1}<\widetilde{v}_{0} .
$$

Comparing expressions (16) and (13), this is the case if

$$
\frac{k-c}{2}+\frac{\bar{v}}{2}<\underline{v}+\left\{\frac{1}{2}+\frac{1}{4} \cdot\left(\frac{1}{1+\gamma}\right)\right\} \cdot(\bar{v}-\underline{v})+\frac{(k-c)-\underline{v}}{4},
$$

or, equivalently, if

$$
\frac{k-c}{4}<\frac{\underline{v}}{4}+\frac{1}{4} \cdot\left(\frac{1}{1+\gamma}\right) \cdot(\bar{v}-\underline{v}) \Leftrightarrow F_{u}(k-c)<\frac{1}{1+\gamma}=\frac{M_{d}}{M_{d}+M_{m}} .
$$

\section{References}

Aguzzoni, L., Buccirossi, P., Ciari, L., Corts, K., Tognoni, M., Spagnolo, G. \& Vitale, C., Zampa, G. L., di Giò, A. (2012, September). Can 'fair' prices be unfair? A review of price relationship agreements. Retrieved from http://www.oft.gov.uk/shared_oft/research/ OFT1438.pdf

Amazon.co.uk. (2011, October). Price parity. Retrieved from http://www.amazon.co.uk/ $\mathrm{gp} / \mathrm{help} /$ customer/display $\cdot \mathrm{html}$ ? ie=UTF8\&nodeId=200458310

Anderson, C. K. (2011). Search, OTAs, and online booking: An expanded analysis of the billboard effect. Cornell Hospitality Report, 11(8).

Arbatskaya, M. (2001). Can low-price guarantees deter entry? International Journal of Industrial Organization, 19(9), 1387-1406.

Armstrong, M. (2006). Competition in two-sided markets. The RAND Journal of Economics, 37(3), 668-691.

Bolt, W., Jonker, N. \& van Renselaar, C. (2010). Incentives at the counter: An empirical analysis of surcharging card payments and payment behaviour in the netherlands. Journal of Banking \& Finance, 34(8), 1738-1744.

Bourreau, M. \& Verdier, M. (2010). Private cards and the bypass of payment systems by merchants. Journal of Banking \& Finance, 34(8), 1798-1807.

Bundeskartellamt. (2012, February). Bundeskartellamt examines HRS best price clause. Retrieved from http://www. bundeskartellamt.de/wEnglisch/download/ pdf/Presse/2012/2012-02-10_PR_HRS_E.pdf

Chintagunta, P. K., Chu, J. \& Cebollada, J. (2012). Quantifying transaction costs in online/ offline grocery channel choice. Marketing Science, 31(1), 96-114.

Cooper, T. E. (1986). Most-favored-customer pricing and tacit collusion. The RAND Journal of Economics, 17(3), 377-388. 
De Los Santos, B., Hortaçsu, A. \& Wildenbeest, M. R. (2012). Testing models of consumer search using data on web browsing and purchasing behavior. American Economic Review, 102(6), 2955-2980.

Economides, N. \& Henriques, D. (2011). To surcharge or not to surcharge? A two-sided market perspective of the no-surcharge rule. SSRN eLibrary. Retrieved from http://ssrn . com/paper $=1912951$

European Commission. (2007a). Payment services directive 2007/64/ec. Retrieved from http://ec.europa.eu/internal_market/payments/framework/psd_en.htm

European Commission. (2007b). Report on the retail banking sector inquiry. Retrieved from http://ec.europa.eu/competition/sectors/financial_services/inquiries/ retail.html

Gans, J. S. (2012). Mobile application pricing. Information Economics and Policy, 24(1), 5259.

Gans, J. S. \& King, S. P. (2003). The neutrality of interchange fees in payment systems. Topics in Economic Analysis \& Policy, 3(1), 1-16.

HRS.com. (2012, August). HRS Best-Price Guarantee. Retrieved from http://www . hrs . com/ web3/showCmsPage.do;?client=en\&pageId=standard-01869

Hviid, M. \& Shaffer, G. (2010). Matching own prices, rivals' prices or both? The Journal of Industrial Economics, 58(3), 479-506.

Jonker, N. (2011). Card acceptance and surcharging: The role of costs and competition. Review of Network Economics, 10(2), Art. 4.

Jullien, B. (2012). Two-sided B2B platforms. In M. Peitz \& J. Waldfogel (Eds.), The Oxford handbook of the digital economy (pp. 161-185). Oxford University Press.

Langlet, M. \& Uhlenbrock, J. (2011). Merchant fee determination in unitary networks with price competition among merchants. SSRN eLibrary. Retrieved from http://ssrn. com/paper $=1754394$

Miao, C.-H. (2011). Do card users benefit from the use of proportional fees? Mimeo.

Moorthy, S. \& Winter, R. A. (2006). Price-matching guarantees. The RAND Journal of Economics, 37(2), 449-465.

Muthers, J. \& Wismer, S. (2013). Why do platforms charge proportional fees? Commitment and seller participation. SSRN eLibrary. Retrieved from http://papers.ssrn.com/ paper $=2204498$

Neilson, W. S. \& Winter, H. (1993). Bilateral most-favored-customer pricing and collusion. The RAND Journal of Economics, 24(1), 147-155.

Office of Fair Trading. (2012, July). OFT issues statement of objections against Booking.com, Expedia and Intercontinental Hotels Group. Retrieved from http://www . oft .gov . uk/ news-and-updates/press/2012/65-12

Rochet, J.-C. \& Tirole, J. (2002). Cooperation among competitors: Some economics of payment card associations. The RAND Journal of Economics, 33(4), 549-570.

Rochet, J.-C. \& Tirole, J. (2006). Two-sided markets: A progress report. The RAND Journal of Economics, 37(3), 645-667. 
Salop, S. C. (1979). Monopolistic competition with outside goods. The Bell Journal of Economics, 10(1), 141-156.

Schnitzer, M. (1994). Dynamic duopoly with best-price clauses. The RAND Journal of Economics, 25(1), 186-196.

Schwartz, M. \& Vincent, D. R. (2006). The no surcharge rule and card user rebates: Vertical control by a payment network. Review of Network Economics, 5(1), 72-102.

Shy, O. \& Wang, Z. (2011). Why do payment card networks charge proportional fees? American Economic Review, 101(4), 1575-1590.

Verdier, M. (2011). Interchange fees in payment card systems: A survey of the literature. Journal of Economic Surveys, 25(2), 273-297.

Wang, Z. \& Wright, J. (2012). Ad-valorem platform fees and efficient price discrimination. FRB Richmond Working Paper, 12-08.

Wills, M. (2010, August). EU responds to Amazon price parity complaint. Retrieved from http://book-selling.blogspot.com/2010/08/ eu-responds-to-amazon-price-parity.html

Wolk, A. \& Ebling, C. (2010). Multi-channel price differentiation: An empirical investigation of existence and causes. International Journal of Research in Marketing, 27(2), 142-150.

Wright, J. (2003). Optimal card payment systems. European Economic Review, 47(4), 587612. 